\title{
EL MAESTRO TRASMERANO PEDRO DE MORLOTE Y LA NUEVA CABECERA DE LA CATEDRAL DE MONDOÑEDO $(1598-1603)^{1}$
}

Javier Gómez Darriba

Universidade de Santiago de Compostela

Data recepción: 2018/05/30

Data aceptación: 2018/06/18

Contacto autor: javier.gomez.darriba@usc.es

ORCID: https://orcid.org/0000-0001-6712-2983

\section{RESUMEN}

La catedral de Mondoñedo asistió a la mayor reforma arquitectónica de su historia entre 1598 y 1603. Entonces se demolió parte de su fábrica medieval para aumentar un tercio su tamaño gracias a la erección de una nueva cabecera, diseñada por el maestro de cantería trasmerano Pedro de Morlote. Analizaremos los motivos por los que se hizo esta obra, así como su diseño, las fases de construcción, los modelos que se siguieron y el taller que la levantó.

Palabras clave: catedral de Mondoñedo, Pedro de Morlote, Gonzalo Gutiérrez Mantilla, Cabildo de Mondoñedo, Nicolás Beche

\section{ABSTRACT}

Between 1598 and 1603, Mondoñedo Cathedral underwent the greatest architectural restructuring in its history, when part of its medieval structure was demolished to increase its size by a third thanks to the erection of a new chevet, designed by the quarry master Pedro de Morlote of Trasmiera (Cantabria). We will assess the factors that led to its construction, its design, the construction process, the models that were followed, and the workshop that erected it.

Keywords: Mondoñedo Cathedral, Pedro de Morlote, Gonzalo Gutiérrez Mantilla, the canonry of Mondoñedo, Nicolás Beche

De la vieja a la nueva catedral de Mondoñedo: el plan y los motivos para su reforma

El año de 1598 fue verdaderamente complicado para la ciudad de Mondoñedo, pues estuvo protagonizado por un brote de peste que afectó a parte de su población². Pero al mismo tiempo resultó una fecha trascendental para su edificio más emblemático, la catedral de Nuestra Señora de la Asunción, pues a partir de entonces se acometió en ella la mayor ampliación de toda su historia. Desde su dedicación en el siglo XIII apenas había sufrido alteraciones en lo que a tamaño se refiere, por lo que el impacto urbano de las mismas había resultado prácticamente nulo. La más significativa había tenido lugar en 1548 durante el episcopado del humanista Diego de Soto. Este prelado auspició una reforma que afectó a la fachada y a la Plaza pública de la ciudad. Con la pretensión de eliminar las escaleras de fábrica que había en la iglesia nada más traspasar su portada y con la idea de agrandar dicha puerta, ordenó rebajar la cota de la Plaza inmediata a esta y construir unas nuevas escaleras en el exterior, de tal forma que desde la Plaza se descendiese por ellas hasta el 


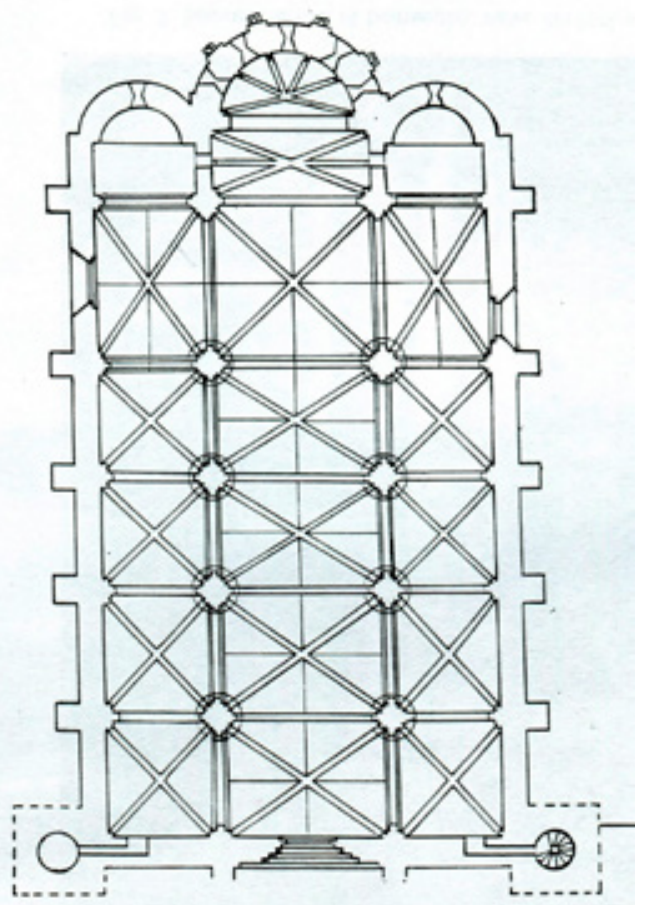

Fig. 1. Planta de la catedral de Mondoñedo en el siglo XIII según E. Carrero Santamaría

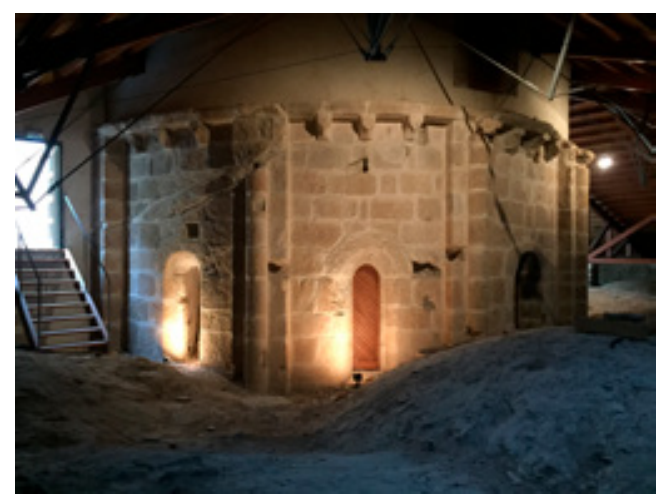

Fig. 2. Ábside mayor de la catedral de Mondoñedo visto sobre el trasdós de las bóvedas de la cabecera

nuevo atrio, dispuesto ahora al mismo nivel que el suelo del templo3. Pero dicha intervención nada tuvo que ver con la emprendida a partir de 1598, pues esta afectó al costado oriental del edificio y aumentó su tamaño en un tercio ${ }^{4}$. A la reforma se le conoció como la "obra del traschoro", y a su proyectista y director, Pedro de Morlote, como el "maestro del traschoro" 5 . La utilización de este vocablo como sinónimo de girola o deambulatorio era común entonces y en stricto sensu aludía a la parte trasera del coro catedralicio ${ }^{6}$. Ello no implica que en el caso mindoniense las celebraciones corales se celebrasen tras la capilla mayor

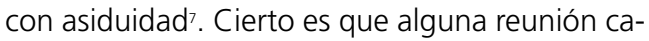
pitular sí se producía en ella, pero también en otros espacios, pues este Cabildo era propenso a reunirse en los sitios más insospechados de su iglesia y palacio episcopals. Sea como fuere no olvidemos que las dos últimas sillerías corales, de los siglos XV y XVI respectivamente, se ubicaron en la nave central'.

Hasta la fecha de 1598 la catedral presentaba un plan basilical formado por tres naves de cuatro tramos. Seguía a estas un crucero no desarrollado en planta coronado por una cabecera triple. El testero lo presidía un ábside central semicircular que alojaba la capilla mayor, y lo flanqueaban dos absidiolos que desaparecieron fruto de la ampliación. Por esta razón se ignora con certeza el perfil que tendrían, aunque la historiografía defiende de forma mayoritaria que eran semicirculares $^{10}$ (figs. 1-2). El del lado de la Epístola, dedicado primitivamente a San Martín, tenía entonces por titular al Santo Cristo de las Ánimas o Santo Crucifijo, mientras que el del Evangelio cobijaba la única parroquia de la ciudad, la de Santiago. A diferencia de buena parte de las catedrales de España, la de Mondoñedo apenas vio cómo su cabecera se congestionaba de múltiples capillas y sacristías entre los siglos XIV y XVI. A la de San Martín se anexó la de la Magdalena en el trescientos, cuya entrada daba al claustro. Esta debía de tener un cierre poligonal, al menos así se sobreentiende al visualizar los nervios de la bóveda que todavía conserva. Y haciendo ángulo con ella, hacia el este, se hallaba la capilla de San Andrés, conocida también como Palacio de los Caballeros por las muchas sepulturas de caballeros que había en su suelo"1. Levantada también en el siglo XIV aunque reformada en la segunda mitad del XVI, cumplía habitualmente las funciones de sala capitular ${ }^{12}$, y en el momento de la reforma también las de sacristía ${ }^{13}$, detalle muy a tener en cuenta porque lo han obviado aquellos autores que han intentado describir cuántas sacristías había en la vieja cabecera y qué lugar ocupaban. Realmente nadie se ha puesto de acuerdo al respecto, y ello es lógico, porque lo ambiguo de 
la documentación dificulta con creces su exacta localización ${ }^{14}$. Detrás de la cabecera había unas huertas propiedad del obispo y del Cabildo que alcanzaban hasta la muralla medieval. Desde antiguo a esta zona se le conocía como Pumar ${ }^{15}$. De hecho, la cerca se hallaba perforada por la Puerta del Pumar y la atravesaba a su vez la Rúa del Pumar, que desde dicha puerta subía hasta desembocar en la Plaza, discurriendo en paralelo a los citados solares y a la catedral, dejando a un lado a la capilla de Santiago y a continuación a la Puerta Pequeña, nombre con que se conocía al acceso septentrional del templo sito en su transepto ${ }^{16}$.

Conocido el aspecto que presentaba el costado oriental de la catedral a finales del siglo XVI, hemos de decir que el interés capitular por operar allí una nueva cabecera hubo de retrotraerse como mínimo a 1575. El 1 de julio de aquel año el arcediano Diego Maldonado de Paz dejó en una de sus cláusulas testamentarias 200 ducados "para ayuda del trascoro q deseo se haga en esta santa yglesia para quando se hiziere". Debía albergar cierto ánimo porque las obras se iniciasen pronto, pues recalcaba que de no principiarse en el transcurso de un año su dote se rebajaría a la mitad, o sea, a 100 ducados, que serían ahora destinados a dotar una misa de réquiem anual en el día de su aniversario. Fallecido este canónigo sus albaceas incumplieron todas las mandas respecto al "comyenzo del trascoro", y lo hicieron hasta tal extremo que en el verano de 1579 fueron declarados incursos en excomunión por no haber abonado siquiera los 100 ducados a que estaban obligados ${ }^{17}$.

Es posible que la iniciativa de la nueva cabecera se diluyese con el paso de los años, pues aparte de no tener más noticias de esta, sí nos consta que en 1584 el obispo Isidro Caja de Lajara, tras girar una visita a la catedral, ordenó " $q$ se trate de haçer una secreta detras de la capilla de Sanctiago o donde mas conmodidad ubiere". Ignoramos si llegaron a efectuarse las letrinas en tal ubicación, pero el simple hecho de idear un espacio minúsculo y servicial junto a la capilla de Santiago da a entender que por entonces no estaba en su mente el acometer una gran girola ${ }^{18}$. Pasada una década, el 18 de agosto de 1593 se celebró una reunión capitular a la que asistió un importante mercader afincado en Mondoñedo:
Nicolás Beche. Este notició a los canónigos su deseo de "hacer una Capilla con reja en parte [de la catedral] que no hiciese daño", y que una vez construida le concedería al Cabildo 2.000 ducados para "que los emplease, y dixese las Misas qe le pareciese [...] de manera que el Cav. ${ }^{\circ}$ quedase contento" ${ }^{19}$. Los canónigos hubieron de ver con buenos ojos una fundación tan generosa como esta, pues aparte de hacerse en pro del culto divino suponía un jugoso beneficio para unas arcas siempre maltrechas. De ahí que el 15 de septiembre estudiasen la "utilidad y pobecho" que para "nos y nros suçesores y pa nra mesa capitular y fabrica" acarrearía el escriturar la dotación. En virtud de la misma Nicolás Beche derrocaría "la pared de la dha catradal yglya en cierto lugar senalado" y cubriría "de bobeda" el nuevo recinto, al cual concedería las piezas de orfebrería y demás ornamentos que le fueren necesarios ${ }^{20}$. Nada más volvemos a saber de esta petición hasta finales de 1597, fecha en que el Cabildo comisionó a tres de sus miembros para que la tratasen ${ }^{21}$. Finalmente, el 14 de enero de 1598, los capitulares y el obispo Gonzalo Gutiérrez Mantilla declararon ante notario que tenían acordado realizar en la catedral un "trascoro por la gran falta que ay del p. ampliarla y perfiçionarla y azer los altares que en ella faltan", y dada la "poca renta y posibilidad" con que contaba la fábrica, el prelado, "mobido con santo celo", se comprometió a ofrecer para ayuda de la obra 800 ducados en cuatro años - 200 anuales. Los canónigos siguieron su ejemplo y acordaron entregar 400 - 100 por cada uno de los cuatro años ${ }^{22}$. Tres semanas después el pontífice entró en plena reunión capitular trayendo consigo "la traza del trascoro y los ofiçiales", ajustándose la obra en 24.000 reales ${ }^{23}$. Y el 22 de abril el contrato se adjudicó al autor que había firmado la traza, que no era otro que el "maestro de canteria" Pedro de Morlote, trasmerano pero residente en Monforte de Lemos $^{24}$. No existe constancia de que se abriesen pujas para rematar la obra. Hasta es posible que el obispo cántabro se la adjudicase directamente a su paisano ${ }^{25}$. Morlote se comprometió a realizar un deambulatorio compuesto por "doçe capillas" que medirían "diez y ocho pies en quadrado". De la docena, ocho se colocarían "por la parte de dentro arrimadas a la pared de la dha capilla mor", mientras que las cuatro restantes habrían 
de "salir afuera del dho trascoro en la cabezera que caen a la huerta del palaçio episcopal y a la pe de la otra huerta [...]". El vocablo "capilla" por entonces no solo era sinónimo de recinto litúrgico, sino también de tramo abovedado. Y precisamente en el caso que nos ocupa tiene esta última acepción. Por ello, cuando el contrato menciona la hechura de "doçe capillas", se está refiriendo a otros tantos tramos cubiertos por bóvedas ${ }^{26}$. Los ocho primeros abrazarían por entero el ábside de la capilla mayor y conformarían el tránsito de la girola, mientras que los otros cuatro, abiertos a esta, albergarían sus respectivas capillas y la cerrarían por su flanco oriental. A todos ellos se sumaría un decimotercer tramo ligeramente más pequeño, de "diez y ocho pies en largo y doze en ancho" que se situaría "al lado de la dha capilla de santo[Santiago]". Pedro de Morlote se comprometió a iniciar esta ampliación en el mes de mayo y a tenerla terminada en el plazo de dos años ${ }^{27}$. Pero a finales de noviembre el nuevo fabriquero manifestó a los demás canónigos "que el maestre de la obra queria azer una capellanía myor de sacrystia" y el Cabildo decidió estudiar este asunto ${ }^{28}$. Pasados cinco días se efectuó un nuevo contrato con Morlote "sobre las sacristias y nesçess as [necesarias]". Dicha escritura demuestra que en un primer momento "estaba tratado que hiziese la sacristia mayor y menor açia la Capilla del señor santo andres donde al presente estaba el cabildo", es decir, hacia el flanco meridional de la catedral, junto al claustro; y ahora se decidía mudarla al lado opuesto "por paresçerles [a los canónigos y al obispo] que las dhas sacrystia mayor y menor estarian mejor a la $\mathrm{p}^{\text {te }}$ de la nabe donde al presente esta la capilla del senor santiago" 29 .

Con anterioridad a este acuerdo, cuando ni apenas había transcurrido un mes de la firma del primer contrato, los cumplidores del testamento de Nicolás Beche, entre los cuales se hallaba el obispo, se reunieron con el Cabildo el 17 de mayo a fin de materializar las cláusulas solicitadas por el mercader. De modo que hicieron entrega de 2.000 escudos de oro con que dotar una capilla en la que se habría de rezar una misa diaria y otra cantada en el día de san Nicolás - patrono de Beche. Quedó entonces confirmado que dicho recinto sería una de las nuevas capillas del deambulatorio, aunque sin especificarse cuál. Mientras esta no se concluyese, las homilías se dirían en el altar de Santa Ana y/o en el de San Sebastián. Una vez terminada, los albaceas podrían colocar en su pared un letrero que referenciase al fundador y a su dotación.

Las obras de la cabecera se iniciaron a lo largo del verano de 1598. En este tiempo los testamentarios de Beche destinaron a ellas 11.000 reales provenientes del préstamo que la Ciudad había contraído con el obispo por la compra del trigo, y otros 8.759 que estaban en poder del propio prelado y de su mayordomo Juan Gutiérrez de Torices, arcediano de Montenegro y primo suyo como hemos dicho ${ }^{30}$. De estos fondos comenzaron a salir las libranzas que paulatinamente se le otorgaban a Morlote por sus trabajos, y también todo lo necesario para que el fabriquero pagase el acarreo de piedra, cal y arena. Igualmente se aprobó como recinto privado del difunto Beche la capilla del ángulo del lado de la Epístola puesta bajo la advocación del Santo Crucifijo. Esta mantendría la titularidad del absidiolo medieval sito en el mismo lado, cuyo derribo, por cierto, era inminente. También heredaría su "rexa de fierro dorada". En su interior se colocaría la mencionada "piedra con el letrero" referencial al fundador, mientras que en el exterior un campanario, tal y como lo había testado Beche. Todo ello habría de estar terminado en septiembre de 1599. La tardanza por concretar la dotación de esta capilla se debió al difícil año que vivió la urbe: "si se dexo de hacer la dha capilla antes de aora como lo mando el dho difumto fue por los casos fortuytos que ubo de hanbre y peste en esta ciudad de mondo desde seys meses a esta parte", es decir, desde marzo hasta septiembre de 1598 ${ }^{31}$.

La Iglesia mindoniense tenía razones suficientes para engrandecer su templo y adaptarlo a los nuevos tiempos. La propia documentación revela que el "trascoro" se hizo "por la gran falta que ay del p. ampliarla y perfiçionarla [la iglesia/ catedral] y azer los altares que en ella faltan". No cabe duda de que la expresión "ampliarla y perfiçionarla" es ambivalente, pues tanto puede hacer referencia a que el deambulatorio engrandecería el modesto tamaño del templo, como a que las rentas de la fábrica crecerían gracias a su erección. Y es que la aparición de nuevas capillas y naves en torno a un lugar tan privilegiado como 


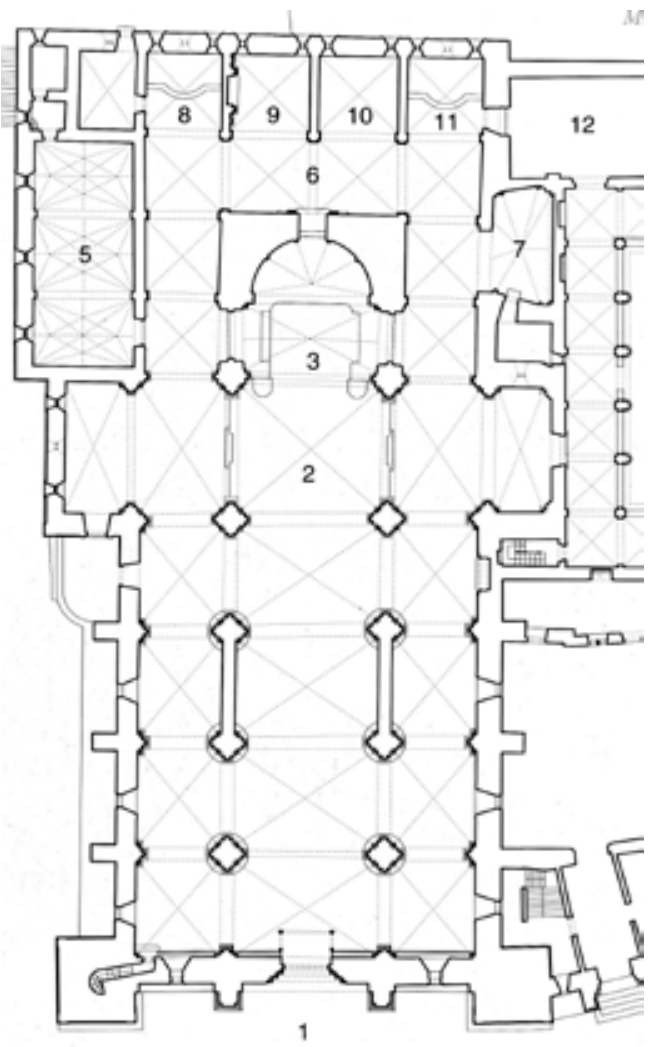

Fig. 3. Planta actual de la catedral de Mondoñedo

el altar mayor facilitaría el interés de la oligarquía local por enterrarse allí, con lo cual, a largo plazo, las rentas de la fábrica se verían recrecidas. De hecho, tengo la impresión de que la génesis de esta girola devino de forma un tanto circunstancial del particular interés de un comerciante como Nicolás Beche por erigir una capilla privada. No hay más que comparar la generosa dotación que legó a esta Iglesia con el precio en que se presupuestó el "traschoro", para asumir que sin ese dinero difícilmente se pudiera haber materializado entonces. No olvidemos además que prelado y Cabildo manifestaron ante notario su deseo de hacer la cabecera justo un mes después de que se estudiase el realizar la capilla de Beche. En este sentido, hay que destacar y mucho el hecho de que el obispo Gutiérrez Mantilla fuese el albacea de este mercader, y en consecuencia estuviese obligado a cumplir lo solicitado en su testamento. Ello explica el gran interés que siguió mostrando por el avance de las obras una vez se trasladó a

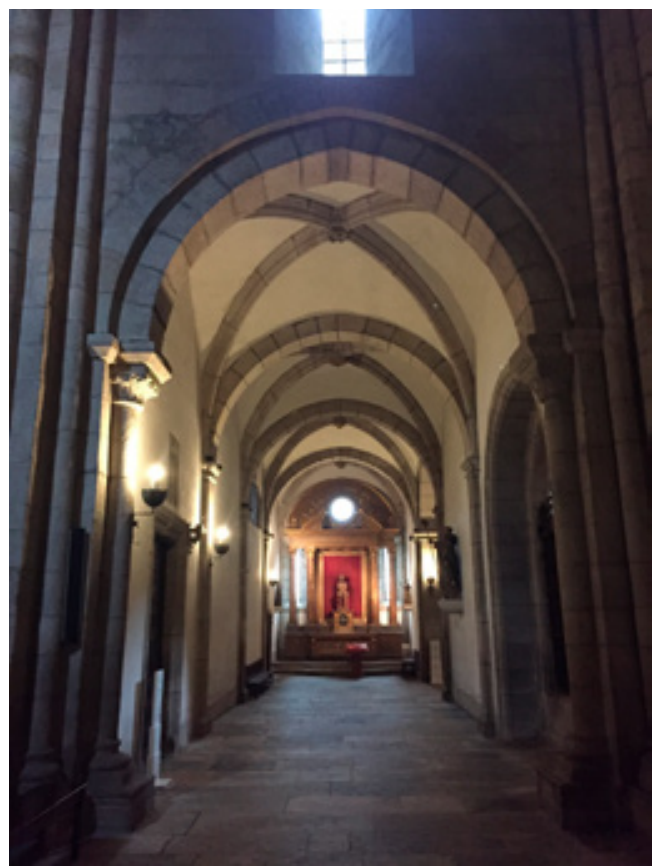

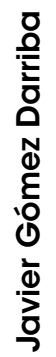

Fig. 4. Nave del Evangelio en la girola de la catedral de Mondoñedo

la diócesis de Oviedo -como luego veremos. Efectivamente, aparte de Beche, otras renombradas personalidades de la esfera mindoniense no se demoraron en demasía a la hora de adquirir las nuevas capillas y convertirlas en recinto propio para su sepultura y la de sus descendientes. Es el caso del regidor Álvaro Pérez Osorio en $1615^{32}$.

\section{El diseño de la nueva cabecera}

Pedro de Morlote configuró una cabecera de planta cuadrangular que pese a albergar múltiples estancias destaca por su carácter homogéneo e integrador para con el edificio anterior (fig. 3). De hecho las propias naves de la girola casi parecen prolongaciones de las medievales. Este efecto lo consiguió gracias a la reiteración de unas bóvedas cuatripartitas de similar altura que las pretéritas y de unos arcos un tanto desiguales que, aunque tienden hacia el medio punto, tampoco distorsionan en demasía respecto a los medievales dado que estos también carecen de una perfecta simetría. Para todo ello el maestro cántabro derribó los absidiolos primitivos aunque conservando su arco ojival de ingreso, convertido 


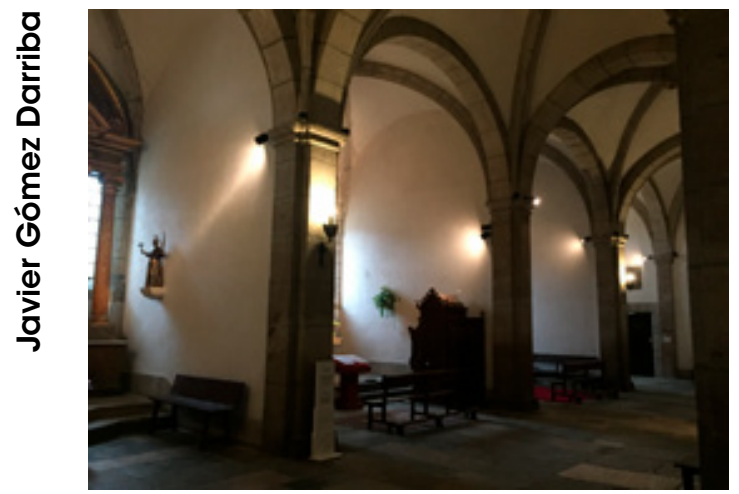

Fig. 5. Capillas abiertas a la nave perpendicular de la girola de la catedral de Mondoñedo

ahora en el acceso a las naves de la girola. Dichas naves y las cuatro capillas que a ellas se abren las articuló con pilastras toscanas, cuyos capiteles fusionan las molduras de sus flancos con unas minúsculas ménsulas de cuarto de círculo en las que se apoyan las nervaduras de las bóvedas (figs. 4-5). Estas mensulillas no aparecen junto a las semicolumnas medievales del ingreso, pues allí los nervios reposan en los ábacos de los capiteles originales y en lo poco que se conserva de las impostas primigenias. En el lado meridional del deambulatorio demolió parcialmente el testero de la capilla de la Magdalena, y ello dio lugar a un gran arco de medio punto comunicado con la girola y apoyado en pilastras de idéntico formato a las citadas ${ }^{33}$ (fig. 6). En el arco hubo de disponer la reja quinientista sobre zócalos de cantería labrada, en cuya faz interior aparece el nombre del obispo Diego de Soto y la data de 1548 ${ }^{34}$. Al este de dicha capilla, como sabemos, se hallaba la sala capitular dedicada a San Andrés. Esta también debió ser cercenada por el mismo flanco que la anterior, con lo cual, hubo de acotarse su tamaño y de abrirse en su nueva pared la puerta cuadrangular que pasó a comunicarla con la capilla fundada por Nicolás Beche. En el lado opuesto del deambulatorio el maestro levantó la sacristía mayor, la sacristía de la parroquial de Santiago y las necesarias. La sacristía capitular la abrió al primer tramo de la nave por medio de una puerta cuadrangular de marco moldurado, orejeras, y ménsula en la clave del dintel. La estancia presenta una planta rectangular de tres tramos. La cubre una bóveda de terceletes atada por una espina de pez y ritmada por arcos de

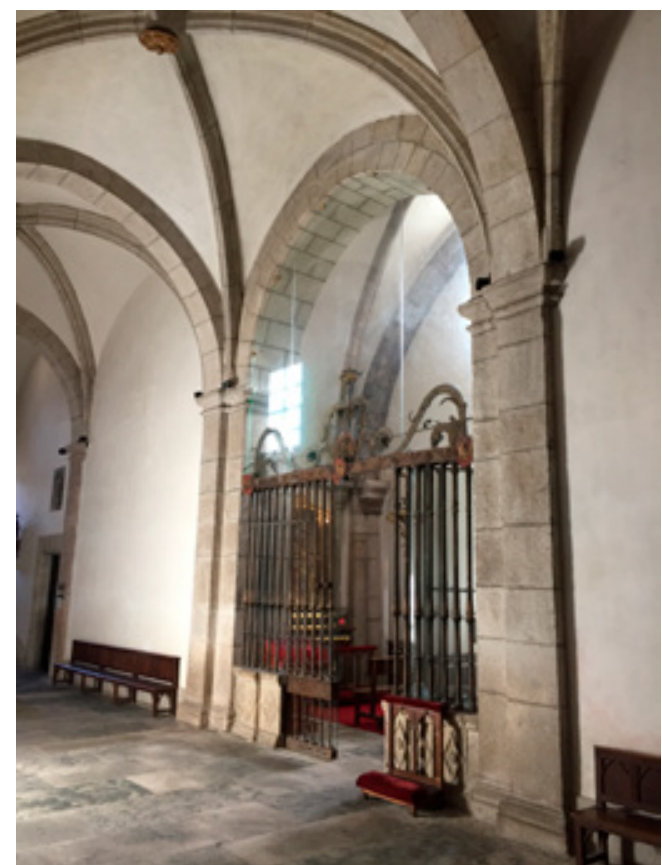

Fig. 6. Arco de ingreso a la capilla de la Magdalena de la catedral de Mondoñedo

medio punto ligeramente apuntados (fig. 8). Sus nervios convergen tanto en los arcos ojivales de los muros laterales como en las medias pilastras, cuyo capitel y mensulillas anejas lucen un idéntico formato a las del deambulatorio. Ahora bien, que sus fustes no alcancen el suelo y que su remate sea multicurvilíneo y con una placa superpuesta invita a pensar a que se cercenaron a principios de la década de 1770, quizá con el objeto de ubicar más cómodamente la nueva cajonera ${ }^{35}$. En las juntas de los terceletes se inscriben unos medallones en los que tiene cabida la única ornamentación de todo el conjunto. Así, en el primer tramo aparecen motivos florales y los monogramas de Cristo y María. En el segundo, aparte de los elementos fitomorfos mencionados se aprecia una cruz de Alcántara y un águila. Mientras que en el tercero y último más motivos vegetales y una estrella de David, un corazón atravesado por un puñal y un jarrón. Tras la sacristía hay dos minúsculas dependencias comunicadas entre sí y con esta. Contienen una estrecha bóveda de cañón y en su origen debieron de ser las letrinas. A su lado se halla la sacristía de la parroquial de 


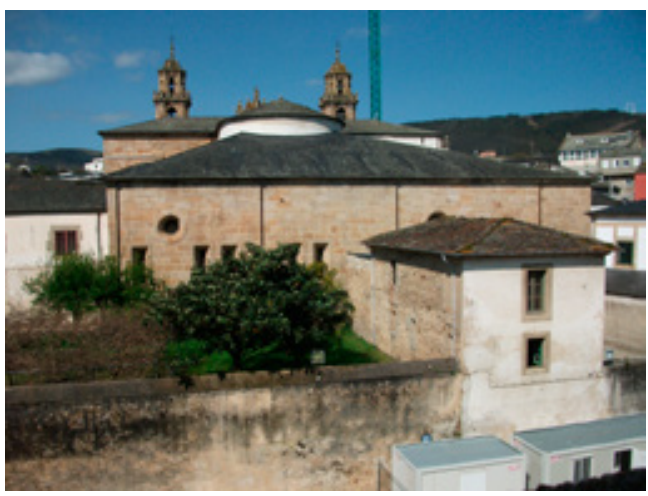

Fig. 7. Exterior de la cabecera de la catedral de Mondoñedo

Santiago, abierta a su correspondiente capilla y cubierta por una bóveda de crucería.

Una de las condiciones del contrato de la cabecera especifica emplazar la capilla de las reliquias en la capilla de San Juan, abierta al claustro, y en caso de no ser posible conducirla a la girola, junto a la capilla contigua a la de Santiago ${ }^{36}$. Desconocemos dónde se ubicó dicho receptáculo y si se llegó a realizar siquiera. De lo que no hay duda es de que entre 1614 y 1615 , durante el episcopado de Alfonso Mesía de Tovar, se perforó en medio de la pared que cierra la capilla mayor una hornacina a modo de trasaltar a fin de cobijar la recién llegada reliquia de san Rosendo, patrono de la diócesis ${ }^{37}$.

El exterior de la cabecera llama la atención, una vez más, por su sentido unitario, pues de forma homogénea aglutina las cuatro capillas, las dos sacristías y las letrinas (fig. 7). Asimismo, cabe destacar su austeridad formal. Nada articula ni exorna sus recios muros de cantería de cuidada estereotomía. En ellos solamente se abren catorce vanos rectangulares que iluminan sus estancias y otros dos circulares que hacen lo propio con las capillas de los extremos, aportando mayor diafanidad a las naves paralelas de la girola. Otro aspecto a recalcar es su repercusión en la malla viaria. Realmente no fue demasiado notable, pues aunque el templo creció enormemente lo hizo ocupando un solar hasta entonces conformado por huertas. De todos modos el flanco correspondiente a la sacristía mayor sí mudó el perfil de la parte intramuros de la Rúa del Pumar, generando un esconce en relación con el transepto.

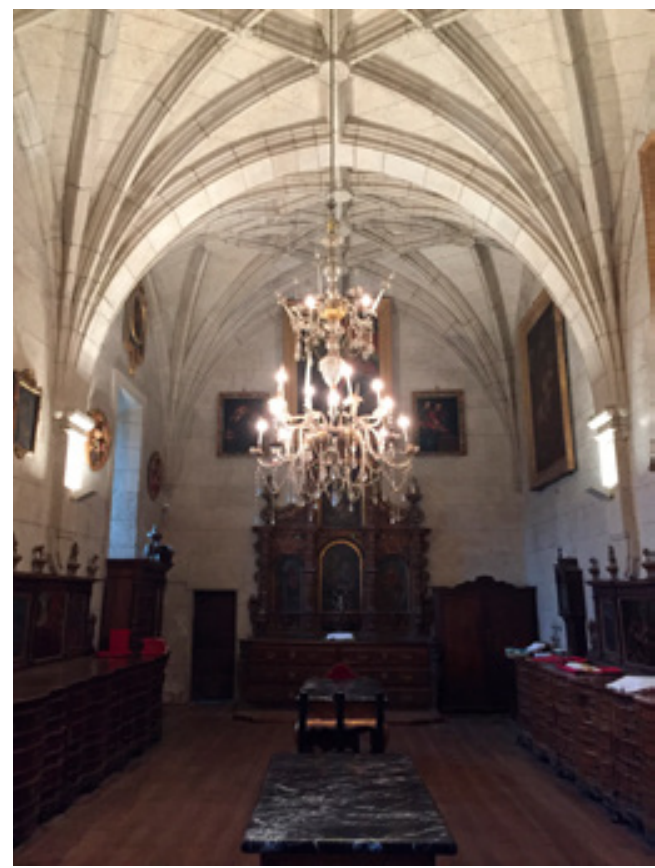

Fig. 8. Sacristía de la catedral de Mondoñedo

\section{El avance de las obras}

Como ya hemos referido se iniciaron en el verano de 1598. En octubre los capitulares acordaron el modo de financiarlas, y en noviembre el obispo advirtió al Cabildo que no podía entregar los 800 ducados que había prometido en enero. Aún así se comprometió a que sus albaceas satisfarían dicha dádiva en caso de que falleciera ${ }^{38}$. Desde 1599 en adelante se conservan abundantes referencias que aluden a los diversos pagos relacionados con las obras ${ }^{39}$, y por fortuna coexisten con otras que atañen al avance de las mismas. Así, sabemos que a finales de abril Morlote se había "ydo fuera". Ignoramos con certeza a dónde, pero lo más probable es que acudiese a Monforte, pues entre 1598 y 1600 dirigió junto con su pariente Juan de la Sierra y luego con Gregorio Fatón las obras del templo benedictino de San Vicente do Pino, y en septiembre de 1600 se convino con Gregorio en que los oficiales Antonio Rodríguez y Pedro Domínguez terminasen la última capilla de la iglesia que ya tenían comenzada $^{40}$. El caso es que con su marcha el taller mindoniense quedó descabezado, y en vista de que los oficiales reclamaban dinero, el fabriquero tuvo 
que ajustar cuentas con el aparejador mientras no regresase el "maestro del trascoro" ${ }^{41}$. En junio Gonzalo Gutiérrez Mantilla, ya como obispo de Oviedo, demostró interés por las obras, algo lógico teniendo en cuenta que no solo había sido su máximo promotor sino que también era albacea de Nicolás Beche. Se escribió con los capitulares y estos decidieron que uno de ellos acudiese hasta la ciudad asturiana para informarle de las mismas $^{42}$. El 25 de dicho mes Morlote ya había vuelto a Mondoñedo, y ante el fabriquero, escribano y testigos, midió con su "compas" y "bordoncillo" la altura de los cimientos realizados "en el canton donde se azen las necess [necesarias]" ${ }^{43}$. Tres semanas después volvía a medir ante notario la altura del "zimyto [cimiento] de la pared y esquina q se aze azerca de la puerta pequena de la dha catredal", es decir, la puerta norte del crucero que salía a la Rúa del Pumar, cuya diferencia de cota respecto a los cimientos era de casi seis metros -veintiún pies ${ }^{44}$. En abril de 1600 Morlote recibió una libranza de 3.000 reales ${ }^{45}$, pero pasados dos meses el fabriquero anunció que no había dinero para la obra, por lo que el depositario Juan Gutiérrez de Torices se ofreció a dar cierta cantidad de lo que debía el ahora obispo de Oviedo ${ }^{46}$. Dicho prelado volvió a cartearse con su antiguo Cabildo en enero de 1601 y reconoció las deudas contraídas con la Iglesia mindoniense. El cuerpo capitular le contestó el 29 de dicho mes informándole que pese a la copiosidad de sus limosnas, "el edifficio es tan costoso y ba tan bueno" que de no depositar más dinero no se lograría "el fin que se desea", pues los últimos 400 ducados donados se estaban agotando, y "trae el maestro cantidad de officiales que como ubiese dineros nos promete con brebedad acabarla". Desde luego las obras habían avanzado, pues le advertía que al presente se hallaban "cubiertas todas las capillas y nabe de el Crucifixo", es decir, las del tránsito meridional de la girola; $y$ que se iba "cerrando la nabe de la Capilla de el Cura", o sea, la septentrional, conducente a la capilla parroquial de Santiago. Que la primera en concluirse fuese la "nabe" y "capilla" del Santo Crucifijo se explica porque urgía cumplir con las aludidas cláusulas testamentarias de Beche ${ }^{47}$. En noviembre de 1601 se seguía extrayendo piedra de Toxoso, perteneciente al coto de Baroncelle ${ }^{48}$, de jurisdicción capitular ${ }^{49}$. Justo un año después, en noviembre de 1602, los canónigos continuaban ingresando fondos para la "ayuda de acabarse el trascoro" 50. El 10 de enero de 1603 Morlote pedía dinero al fabriquero "pa yr a su tierra", y en dicho mes el Cabildo pasaba nuevamente serios apuros para afrontar los pagos ${ }^{51}$. En junio de 1603 la cabecera ya se hallaba terminada en lo fundamental, pues el día 9 el fabriquero Alonso de Cartas remataba su losado y el de la capilla de la Magdalena en el cantero "asistente" Francisco de Castañeda y en los carpinteros Alonso Fernández y Alonso Lorenzo, quienes se obligaron a ponerle fin durante dicho mes y el inmediato de julio a cambio de 80 ducados $^{52}$. Llegado agosto esta actuación todavía no se había efectuado. Muy probablemente ello se debió a no tener liquidez el Cabildo, pues entonces decidió costearla de su bolsillo el obispo Diego González Samaniego adjudicándosela de nuevo a Castañeda ${ }^{53}$. Entre medias, el 27 de junio se le aprobó a Morlote que levantase un "canpanaryo pequeno en la capilla de nycolao beche" en cumplimiento de la solicitud testamentaria del mercader. Para entonces el maestro ya había regresado de "su tierra" 54 . El 20 de agosto el prelado ordenó al Cabildo tasar "la obra que hizo marlote" y traer para tal fin a un maestro de cantería cuya identidad no se desvela ${ }^{55}$. La ceremonia de consagración de la girola hubo de tener lugar en este preciso 1603, por ser la fecha que antiguamente figuraba en la lauda conmemorativa de la obra y que hoy día no se consigue visualizar ${ }^{56}$. A finales de abril de 1604 la capilla del lado de la Epístola se hallaba completamente terminada, pues los capitulares decidieron con el visto bueno del pontífice que "por agora se ponga el sancto crucifixo en la capilla de nicolao veche de prestado y esto mientras fuere voluntad del cabildo y prelado" ${ }^{57}$. Incluso es muy probable que entonces se cerrase dicho recinto con la aludida reja de la antigua capilla ${ }^{58}$. Finalmente, en febrero de 1606, el fabriquero Juan Pardo de Cela acordó de nuevo con Castañeda el "hazer y losar la sacrestia nueba" de la catedral "al modo que esta losado el trascoro", utilizando para ello piedras "del mesmo grandor" que las dispuestas allí. El cantero habría de acabar la obra en marzo y cobraría 4 reales y un cuartillo por cada piedra colocada ${ }^{59}$. A partir de entonces se supone que ya pudo estrenarse con total normalidad, pues en septiembre de 1604 las funciones de sacristía 
aún las cumplía la sala capitular o capilla de San Andrés ${ }^{60}$.

En todo este tiempo el Cabildo tuvo enormes dificultades para poder financiar las obras debido a la penuria económica de la fábrica catedralicia. No en vano la sede mindoniense se hallaba entre las más pobres de España ${ }^{61}$. Así se justifica que obispo y Cabildo aprovechasen la más mínima oportunidad para saldar las deudas contraídas por causa de la nueva cabecera. Por ejemplo, en agosto de 1602 el prelado decidía invertir en ella los 500 ducados legados para obras pías por el difunto Arias González, secretario de la Real Audiencia62. A inicios de 1603 se destinaron 100 más, fruto de la venta de un censo redimido ${ }^{63}$. Pero las dificultades se prolongaron a lo largo del año, confesando Morlote haber cobrado a finales del mismo 4.248 reales desde febrero ${ }^{64}$. $Y$ todavía en noviembre de 1604 se le debían 2.000 al maestro65, aunque hubieron de satisfacérselos inmediatamente merced a los 400 ducados que el clero de la diócesis tenía recaudados para Felipe III y a los que finalmente renunció el monarca. Lógicamente se destinaron al pago de la cabecera por la "grande nesçesidad que tenya la dha fabrica desta dha catradal con el trascoro de nuevo que abia hecho"66.

\section{Pedro de Morlote: personalidad artística y modelos para la cabecera mindoniense}

Pedro de Morlote fue un maestro de cantería vecino de Secadura, lugar perteneciente al Corregimiento de Laredo y a la Merindad de Trasmiera -hoy municipio cántabro de Voto-, que como decenas de paisanos suyos desempeñó su oficio por tierras gallegas entre fines del siglo XVI e inicios del XVII67. El desconocimiento sobre su figura es tal que aún hoy resulta harto complejo discernir cuál de los personajes que compartían nombre y vecindad trazó y ejecutó la cabecera de la catedral de Mondoñedo. La primera noticia que tenemos de él data de abril de 1583. Atañe a los lazos matrimoniales de dos de sus hijos con los vástagos de su vecino y colega Juan de la Sierra, llamados Juan y María de la Sierra. Dicho lo cual, muy probablemente el hijo de este Pedro de Morlote heredase el nombre de su padre, pues el 14 de septiembre de 1621 María de la Sierra recibía en su localidad de Secadura la noticia de que su esposo Pedro de Morlote había fallecido en Mondoñedo y lo habían enterrado en aquella ciudad el 16 de agosto del presente año68. No tenemos mayores datos que aludan a su familia salvo la existencia de dos maestros canteros secadurienses como él que se llamaban Diego de Morlote y Juan de Morlote. El primero vivía en 1599 y el segundo falleció en 1628. Por desgracia se ignora qué grado de parentesco tendrían ${ }^{69}$. Tampoco sabemos de referencias suyas desde la citada fecha del matrimonio hasta mayo de 1588 , en que se cita a un "po de morlote cantero" actuando de testigo en una escritura tomada en el monasterio de Santa María de Meira. Su presencia en el cenobio cisterciense tres años después de que en agosto de 1585 el claustro procesional le fuese rematado a Juan de la Sierra hace probable que entonces lo estuviese levantando a las órdenes de su vecino y pariente. Un lustro más tarde Morlote trabajó bajo la dirección de Juan de la Sierra en el Colegio de Nuestra Señora de la Antigua en la villa de Monforte de Lemos, y como ya hemos apuntado, en los últimos años del siglo XVI ambos volvieron a operar juntos en la iglesia de San Vicente do Pino de dicha localidad. Habida cuenta de los datos aportados y de la existencia de como mínimo dos Pedro de Morlote y dos Juan de la Sierra contemporáneos y emparentados entre sí, cabe la posibilidad de que los presentes en Meira y Monforte fuesen o bien consuegros, o bien cuñados, o incluso suegro y yerno y viceversa. Morlote acudió a Monforte en los primeros días de octubre de 1592 diciendo ser maestro de cantería y vecino de Trasmiera. Lo hizo con el objeto de pujar por las obras del Colegio de Nuestra Señora de la Antigua, fundado por el cardenal Rodrigo de Castro y diseñado por el hermano jesuita Andrés Ruiz y el italiano Vermondo Resta. No logró la adjudicación de las mismas pero formó parte de la amplia plantilla de maestros y canteros que allí trabajaron a lo largo de la década de 1590, pues en abril de 1594 le encomendaron que visitase e hiciese un informe del estado de las obras en dicho colegio, y en junio del mismo año fue contratado junto a su consuegro Juan de la Sierra para llevar a cabo las adiciones de Andrés Ruiz a la traza original. Es posible que en los años siguientes continuase al frente de la fábrica monfortina, dirigida desde 1597 por el también jesuita Juan de Tolosa ${ }^{70}$. De 


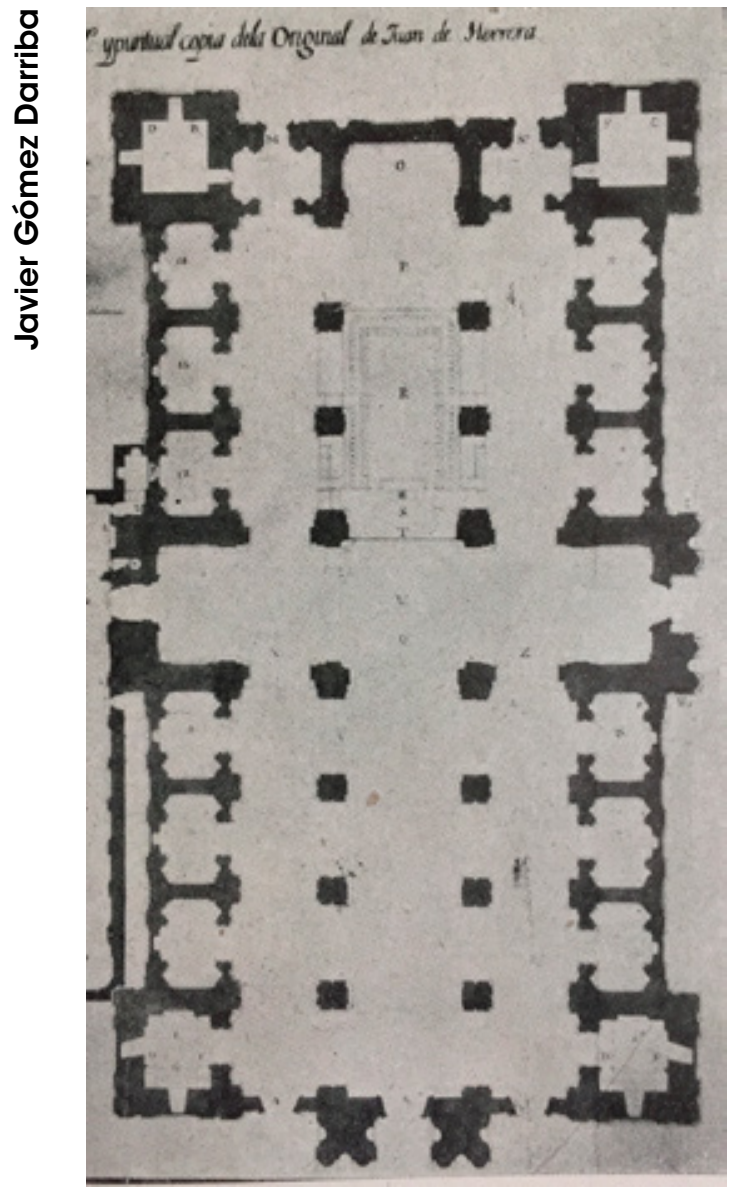

Fig. 9. Copia de la planta de Juan de Herrera para la catedral de Valladolid

lo que no hay duda, como se apuntó, es de su labor en aquella localidad al frente del cenobio benedictino de San Vicente entre 1598 y $1600^{71}$.

Por tanto, cuando a inicios de 1598 fue llamado a Mondoñedo para proyectar y ejecutar la nueva cabecera de la catedral, lo hizo siendo partícipe en Monforte de un contexto estilístico marcado por el clasicismo herreriano llevado hasta allí por arquitectos provenientes de tierras vallisoletanas ${ }^{72}$. Quizá ello explique la adopción de una cabecera rectangular, cuyo formato no solo era inédito en Galicia sino también poco frecuente en España ${ }^{73}$. Dicha tipología la había ideado Juan de Herrera para la colegiata de Valladolid -luego catedral- hacia 158074 (fig. 9), proyecto que, aunque no se llevó a efecto, sí gozó de con- tinuidad en el testero trazado por su discípulo Juan del Ribero Rada para la catedral de Salamanca en 1589, que por cierto contó con el visto bueno del propio Herrera75. Esta posible filiación entre las catedrales castellanas y la mindoniense ya la apuntaron autores como Vila Jato o Rosende Valdés, quienes además, con gran acierto, hicieron hincapié en el pretendido unitarismo formal que vincula la vieja fábrica de Mondoñedo con la nueva, simulando ser toda ella de un mismo momento histórico ${ }^{76}$. En este sentido no hemos de olvidar que los arquitectos y tratadistas italianos del Renacimiento apostaban antes por terminar una obra medieval en el estilo "moderno" o gótico de origen que concluirla en el renacentista -"romano" o "antiguo"-, porque entendían que hacerlo con este último atentaba contra los preceptos vitrubianos ${ }^{77}$. Aparte de la tipología de la cabecera, la nota clasicista más fácilmente visible de la girola mindoniense la constituyen las pilastras que visten sus naves, y que no por casualidad tanto recuerdan a los pilarcillos del claustro de las escuelas del Colegio monfortino. Por el contrario, la nota más arcaizante la supone la cobertura de la sacristía, aunque este tipo de abovedamiento todavía era frecuente en la Galicia finisecular del quinientos e incluso en la de inicios del XVII. De hecho es posible que el propio maestro lo emplease en el desaparecido claustro procesional del monasterio de Meira -siempre y cuando trabajase en él, que como hemos visto cabe la posibilidad de que sí-, pues según Lampérez y Romea sus pandas contaban con "bóvedas de crucería estrellada". De todos modos sin lugar a dudas lo utilizó entre 1598 y 1600 en el templo monfortino de San Vicente do Pino ${ }^{78}$. Además tampoco habría que desechar la posibilidad de que el maestro concibiese la sacristía inspirándose en la levantada durante el episcopado de Diego de Soto a mediados del XVI, que precisamente él mismo derribó a partir de 1598. Incluso no sería de extrañar que los medallones que hoy lucen las juntas de los nervios proviniesen de aquella. Ello lo argumentamos porque el contrato de la obra remarca en distintas ocasiones la necesidad de no incluir elementos decorativos para no aumentar su precio, y de hecho especifica que en la unión de las nervaduras de las bóvedas de las naves no se incluyan "formas"79; y también porque llaman poderosamente la atención aquellos medallones 
donde figuran el monograma mariano y el jarrón, dos símbolos que conforman el blasón del obispo fray Francisco de Santa María Benavides, que gobernó la diócesis entre 1550 y 1558 . Precisamente su escudo aparece entre el de los obispos Gutiérrez Mantilla y González Samaniego en la lauda que conmemora la finalización de la girola, sita en el muro exterior de la sacristía que mira a la nave del Evangelio. ¿Qué hace ahí, en una zona de la catedral no construida en su época, y junto al de los obispos que promovieron y financiaron la cabecera? ${ }^{80}$. Cabe en definitiva la posibilidad de que durante su episcopado se concluyese la sacristía levantada por su antecesor Diego de Soto, y que los motivos ornamentales de esta se reaprovechasen en la levantada por Pedro de Morlote cincuenta años después.

Volviendo a la vinculación estilística con el mundo herreriano, tampoco hemos de desdeñar la posibilidad de que el pontífice que auspició la nueva cabecera conociese mínimamente esta arquitectura, pues vivió en Salamanca entre 1578 y 1583 y a continuación en San Lorenzo del Escorial desde 1583 hasta 1593, fecha esta última en que fue promovido para la sede de Mondoñedo ${ }^{81}$. Desde luego, Gutiérrez Mantilla debía de ser un partidario de este tipo de espacios litúrgicos, pues resulta llamativo que solo dos años después de haber apostado por la girola mindoniense su nuevo Cabildo de Oviedo valorase la necesidad de erigir otra en la catedral, obra que no se hizo efectiva hasta pocos años más tarde y fuera ya de su pontificado ${ }^{82}$.

\section{El taller de Pedro de Morlote}

De entre los muchos canteros que entre finales del siglo XVI y principios del XVII trabajaron en la antigua provincia de Mondoñedo, solo conocemos con certeza la identidad de unos pocos a las órdenes de Pedro de Morlote en las obras de la cabecera catedralicia. Cuando en junio de 1599 el maestro hizo las mediciones de los cimientos de la girola ante el fabriquero y el notario, aparecieron como testigos los siguientes "canteros y trabaxadores en la dha obra" y "rresidentes" en Mondoñedo: Domingo Alonso, Domingo de Fiallega y Francisco de Castañeda83. De los dos primeros no volvemos a tener noticia alguna ${ }^{84}$. De Castañeda, sin embargo, ya dijimos que participó en el losado de la girola en 1603 y en el de la sacristía en 1606, obra esta última que lo cita como "vezino de la merindad de trasmyera" 85 . Además, entre 1603 y 1605 dio condiciones y tomó el arreglo del cercano puente de Viloalles6; y precisamente en este último año se adjudicó la construcción del convento concepcionista de Viveiro ${ }^{87}$. Pero la nómina de pedreros al servicio de Morlote hubo de ser mayor. Así, el 14 de marzo de 1599, compareció ante escribano en representación del canónigo Calonge, y lo hizo para concertarse con el cantero y vecino mindoniense Juan Leal y con el labrador Alonso Valiño a fin de que ambos extrajesen dos sepulturas de "piedra de grano en las canteras de toxoso", que carretearía hasta Mondoñedo el mencionado campesino. Aparecieron como testigos los canteros Jácome y Juan Fatón, hermanos y vecinos de Monforte de Lemos pero "hestante[s]" en Mondoñedo, así como su colega Pedro de Palacio, residente también en dicha ciudad ${ }^{88}$. Seguramente la presencia de todos ellos implique su participación en las obras de la girola. No cabe duda de que Morlote conocía a los hermanos Fatón, pues eran hijos del maestro de cantería Gregorio Fatón y sobrinos de Gonzalo Fatón, y con dichos ascendientes Morlote ya había trabajado en Monforte durante la década de 1590, tanto en el colegio jesuita como en el cenobio benedictino de San Vicente ${ }^{89}$. Lo que no sabemos es si el mencionado Pedro de Palacio es el mismo Pedro de Palacios que en 1592 pujó por la obra de dicho colegio ${ }^{90}$. Un último cantero partícipe en la girola pudo ser Pedro Rodríguez, quien en septiembre de 1601 le debía 12 reales de préstamo y posada a Catalina Rodríguez, vecina mindoniense, la cual dio poder al "mahestro de la obra del trascoro de mon do" Pedro de Morlote para que se los cobrase9". Por último, es de justicia señalar que después de la obra de la cabecera a Morlote le llovieron multitud de encargos en la provincia mindoniense hasta 1621. Todos ellos provenían de instituciones civiles o religiosas y siempre tenían un carácter reparador. Estos nos ofrecen una imagen de Morlote que es la propia de un maestro de obras de segunda fila. Aún así, resultó el cantero más relevante de esta provinciana ciudad durante las dos primeras décadas del siglo XVII. De todos modos, habida cuenta de que su figura todavía no es del todo conocida, nuevos datos documentales podrían hacer tambalear esta opinión. 


\section{NOTAS}

1 Este trabajo se enmarca dentro del proyecto del Ministerio de Economía, Industria y Competitividad Memoria, textos e imágenes. La recuperación del patrimonio perdido para la sociedad de Galicia HAR2014-53893-R, del que son investigadores principales Jesús $A$. Sánchez García y Alfredo Vigo Trasancos. También participa de la ayuda del Programa de consolidación de unidades de investigación competitivas do SUG, modalidade $\mathrm{B}$ : grupos con potencial de crecemento (GPC), concedida por la Xunta de Galicia al grupo de investigación GI-1510 HAAYDU de la Universidad de Santiago de Compostela, del que es coordinador Alfredo Vigo Trasancos y que tiene como $n .^{\circ}$ de expediente ED413B 2016/003. Quiero expresar mi más sincero agradecimiento a un conjunto de personas que desinteresadamente me brindaron todo tipo de facilidades, consejos y datos que contribuyeron en buena medida a confeccionar el presente trabajo. Vaya mi reconocimiento para el M. Iltre. Sr. D. Félix Villares Mouteira, canónigo-archivero de la catedral de Mondoñedo; al erudito mindoniense J. Isidro Fernández Villalba; al campanero de dicha catedral Valentín Insua Palacios; al escultor Fernando Villapol; y a José F. Gutiérrez Morlote, descendiente de Pedro de Morlote.

2 En los primeros meses del año, enterado el Consistorio mindoniense de que las zonas de Betanzos, Sada y Montaos sufrían los avatares de la mortífera peste, y de que Coruña y Pontedeume tenían a guardas velando porque la epidemia no entrase en sus villas, el Ayuntamiento optó por copiar esta medida y colocó vigías en las principales entradas de la urbe. De todos modos en julio ya había penetrado, por lo que se aprobó trasladar a los "apestados" al cercano hospital de San Juan de Seivane, Archivo Municipal de Mondoñedo (a partir de ahora A.M.M.), carp. 923, Libro de Actas (1595-1608), 68r, 71v, $87 r-87 v, 90 v-91 v$. Acerca de dicho brote en Betanzos véase Núñez-Varela y Lendoiro, José Raimundo. 1998. La peste de 1598 en Betanzos de los Caballeros. Ciento y un días de angustia y devoción. Betanzos: Ayuntamiento de
Betanzos, 10, 14-15, 18, 22-24, 26-30, 41-66. En el Archivo de la Catedral de Mondoñedo (a partir de ahora A.C.M.) también se verifican noticias sobre esta epidemia y de la preocupación del Cabildo por proteger la ciudad. Su interés fue tal que comisionaron a un canónigo a que vigilase una de las puertas de la muralla, computándole sus horas de vigilancia por las de asistencia a coro, A.C.M., Actas Capitulares, vol. 8, 102r, 103v, 106v, 107v. Sobre estas cuestiones véase también Cal Pardo, Enrique. 1992. Mondoñedo - Catedral, Ciudad, Obispado - en el siglo XVI. Catálogo de la documentación del Archivo Catedralicio. Santiago de Compostela: Xunta de Galicia, 245, 247-248, 250; Cal Pardo, Enrique. 1999. "Episcopologio mindoniense. Siglo XVI." Estudios Mindonienses 15: 280; Cal Pardo, Enrique. 2000. "Episcopologio mindoniense. Siglo XVII." Estudios Mindonienses 16: 16; Cal Pardo, Enrique. 2003. Episcopologio mindoniense. Santiago de Compostela: CSIC-Xunta de Galicia, Instituto de Estudios Gallegos "Padre Sarmiento", Mondoñedo-Ferrol: Estudios Mindonienses, 393, 403. Sobre esta enfermedad en Mondoñedo se recomienda la lectura de las numerosas entradas que Roberto Reigosa Méndez presenta en su blog registrado https://mondomedieval.blogspot.com.es/, fruto de sus diligentes investigaciones en el A.M.M. Cabe decir que afectó a numerosas poblaciones gallegas, aunque con magnitud dispar, de hecho muchas lograron esquivarla, Saavedra Fernández, Pegerto. 1985. Economía, Política y Sociedad en Galicia: La provincia de Mondoñedo, 1480-1830. Madrid: Xunta de Galicia, 69, 99-101; Nogueira Santiago, Paulo. 2004. "Las epidemias de peste de 1598 y 1599 en Galicia: el ejemplo de la villa de Noia." en Ano Santo Camiño da Xuventude. Mostra Filatélica Xuvenil Nacional. Noia, do 23 de xullo ao 1 de agosto do 2004, 69-76. Noia: Grupo Filatélico e Numismático de Noia; García Oro, José, y Portela Silva, María José. 2005. "A peste, fame et bello, libera nos Domine. Galicia y la peste en el reinado de Felipe II." Semata 17: 231-258.

3 Así lo reseña un manuscrito de 1550 obra de Lope de Frías, antiguo secretario de dicho obispo. Se conser- va en el A.C.M. y cuenta con una copia facsímil en Cal Pardo, Enrique. 1988. "Historia del pontificado de D. Diego de Soto." Estudios Mindonienses 4: 339340, 415-416.

4 La mayor parte de la documentación y planteamientos presentados en este trabajo tienen un carácter inédito. Aun así es de justicia citar a aquellos investigadores que se han acercado al estudio documental de esta obra, siendo el primero Pérez Costanti, Pablo. 1930. Diccionario de artistas que florecieron en Galicia durante los siglos XVI y XVII. Santiago: Seminario C. Central, 397. De todos ellos, Enrique Cal Pardo merece un lugar muy destacado, tanto por su concienzuda labor dentro del A.C.M. como por lo acertado de sus interpretaciones, pues fue pionero en razonar que la sacristía se construyó al mismo tiempo que el deambulatorio y sus capillas - autocorrigiendo una publicación anterior. Antes de él, la historiografía la había creído del episcopado de Diego de Soto, retrasando medio siglo su verdadera fecha, Cal Pardo, Enrique. 1987. "Sacristía y Custodia de la Catedral Basílica de Mondoñedo." Estudios Mindonienses 3: 549-556; Cal Pardo, Mondoñedo -Catedral, Ciudad, Obispado-, 233-234, 239, 240, 244, 246, 248, 257-258, 260, 263, 265, 608, 667, 672-675, 678-679, 681, 684-686, 905, 926-927, 955, 961; Cal Pardo, "Episcopologio mindoniense. Siglo XVI," 277-282; Cal Pardo, "Episcopologio mindoniense. Siglo XVII," 16-18; Cal Pardo, Enrique. 2002. La Catedral de Mondoñedo. Historia. Lugo, 27-29, 76-78; Cal Pardo, Episcopologio mindoniense, 391-395, 403-405; Castro Fernández, Celia. 1993. Estudio iconográfico y estilístico de los capiteles de la catedral de Mondoñedo. Lugo: Diputación Provincial de Lugo, 18-20. Antonio San Cristóbal transcribió los contratos referidos a la cabecera pero con algunas erratas. Además, a lo largo de su artículo demostró un escaso conocimiento de la historia del edificio, con lo cual su texto está salpicado de múltiples fallos históricos, San Cristóbal Sebastián, Antonio. 1998. "IV centenario de la ampliación de la catedral de Mondoñedo." Cuadernos del Museo Mindoniense 16: 47-67. Las transcripciones de A. San Cristóbal se recogen parcialmente 
en Pérez Rodríguez, Fernando. 2000. "O Renacemento." en Fontes escritas para a historia da arquitectura e do urbanismo en Galicia (Séculos XI-XX), coord. por Alfredo Vigo Trasancos, vol. 1, 249-253. Santiago de Compostela: Xunta de Galicia; y también en Cal Pardo, La Catedral de Mondoñedo, 74-76. Asimismo, también acudió a las fuentes originales Carrero Santamaría, Eduardo. 1999. "De la influencia cisterciense en Santa María de Mondoñedo a la evolución arquitectónica de un proyecto basilical románico." en Actas. /l Congreso Internacional sobre el Císter en Galicia y Portugal, vol. 3, 1175-1176. Ourense: Deputación Ourense, Abadías Cistercienses de Galicia, Asturias y León, Concello de Ourense, Caixa Ourense, Santiago de Compostela: Xunta de Galicia; Carrero Santamaría, Eduardo. 2005. Las catedrales de Galicia durante la Edad Media. Claustros y entorno urbano. A Coruña: Fundación Pedro Barrié de la Maza, 145 y ss.

5 Incluso la parte exterior de la cabecera se denomina entonces trascoro o "tras el coro", Archivo Histórico Provincial de Lugo (a partir de ahora A.H.P.L.), Protocolos Notariales, Ribadeo, Jácome Rodríguez de Labrada, leg. 1743-8, 19r; A.C.M., Actas Capitulares, vol. 10, 281r. Casi toda la documentación nomina al maestro Pedro de Morlote como "Marlote", pero él siempre firma como "Morlote".

6 Villaamil y Castro, José. 1889. "Los trascoros de las catedrales." Galicia Diplomática 4, n. 10 (10 de marzo): 75-76; Rivas Carmona, Jesús. 1994. Los trascoros de las catedrales españolas: estudio de una tipología arquitectónica. Murcia: Universidad de Murcia, 45, nota 1. También hay que asumir la ambigüedad implícita del término "coro", como remarca García Lamas, Manuel Antonio. 2015. "Ubicación y fisionomía de cabildos y audiencias públicas en la catedral de Mondoñedo (siglos XIII-XV)." Estudios Mindonienses 30: 409.

7 Sí lo hicieron en los primeros tiempos de la catedral, Cal Pardo, Catedral de Mondoñedo, 15.

8 Aparte de las numerosísimas noticias aportadas en este sentido por Enrique Cal Pardo, conviene repasar, por su carácter compilador, el trabajo de
García Lamas, "Ubicación y fisionomía de cabildos," 391-436.

9 Cal Pardo, "Episcopologio mindoniense. Siglo XVI," 141-142; Cal Pardo, Catedral de Mondoñedo, 17-18; Cal Pardo, Episcopologio Mindoniense, 266-267.

${ }^{10}$ Es el caso de Villaamil y Castro, José. 1865. La Catedral de Mondoñedo. Su historia y descripción, sus pinturas murales, accesorios, moviliario, bronces y orfebrería, vestiduras y ropas sagradas. Madrid: M. Galiano, 5; Murguía, Manuel. 1888. Galicia, Barcelona: Daniel Cortezo y C.A, 1122; Díaz Tie, Marta. 1999. "La catedral medieval de Mondoñedo: arquitectura, escultura y pintura monumental." Estudios Mindonienses 15: 356; Yzquierdo Perrín, Ramón. 2000. "Las Catedrales de la Diócesis de Mondoñedo en la Edad Media." en El legado cultural de la Iglesia Mindoniense. I Congreso do Patrimonio da Diócese de Mondoñedo. Ferrol, 16, 17, 18 de setembro, ed. por Fátima Díaz Platas, Juan Manuel Monterroso Montero, Manuel José Recuero Astray, 135. A Coruña: Universidade da Coruña, Lugo: Diputación de Lugo; Carrero Santamaría, "De la influencia cisterciense," 1172, 1184; Carrero Santamaría, Las catedrales de Galicia, 146; García Lamas, "Ubicación y fisionomía de cabildos," 430, 436. Hay quien considera que solo el ábside central era semicircular, Carro García, Jesús. 1950. Las catedrales gallegas. Buenos Aires: Galicia, 46; San Cristóbal Sebastián, "IV centenario de la ampliación," 47. Parte de dicho ábside se puede visualizar hoy día sobre el trasdós de las bóvedas erectas a partir de 1598 y bajo las actuales cubiertas de la cabecera, realizadas en 1996, Cal Pardo, La Catedral de Mondoñedo, 57. De igual modo, la parte superior del mismo se aprecia desde el exterior. Ello ocurre desde que Francisco Pons-Sorolla renovó por completo la cobertura entre 1964 y 1966. Hasta entonces la cota del tejado era superior y lo ocultaba, Castro Fernández, Belén. 2007. "Francisco Pons-Sorolla y Arnau, arquitecto-restaurador: sus intervenciones en Galicia (1945-1985)." Tesis Doctoral inédita, Universidad de Santiago de Compostela, vol. 2, 461-464.

${ }^{11}$ Con este apelativo se le conocía fundamentalmente en la Edad Media, pero todavía en 1608 se le citaba como "capilla de los caballeros del sor santo andres", A.H.P.L., Protocolos Notariales, Ribadeo, Jácome Rodríguez Labrada, leg. 1762-3, 84r. Y en 1615 como "capilla de $55^{\circ}$ santo andres de los caballeros", A.M.M., carp. 924, Libro de Actas (1609-1622), 178v. Gracias a estos datos pierde fuelle una de las hipótesis alternativas apuntadas por García Lamas a la hora de identificar este espacio, García Lamas, "Ubicación y fisionomía de cabildos," 405.

12 Sobre la capilla de San Andrés véase fundamentalmente Cal Pardo, "Sacristía y Custodia," 551-552; Cal Pardo, Mondoñedo - Catedral, Ciudad, Obispado -, 332, 334, 336, 340, 407, 414, 419, 438, 441, 501, 503, 796; Carrero Santamaría, Las catedrales de Galicia, 146, 148-149, 152-157; García Lamas, "Ubicación y fisionomía de cabildos," 404-406, 436.

13 A.C.M., Protocolos Notariales, arm. 2, est. 2, leg. 3, n. ${ }^{\circ} 21,75 \mathrm{v}$.

14 Sobre dicha discusión véase $\mathrm{Cal}$ Pardo, "Sacristía y Custodia," 549-550; Cal Pardo, "Historia del pontificado," 416-417; Carrero Santamaría, Las catedrales de Galicia, 144-147; García Lamas, "Ubicación y fisionomía de cabildos," 406-408, 436.

15 Entre otras muchas citas, véase Cal Pardo, Enrique. 1990. Catálogo de los documentos medievales, escritos en pergamino, del Archivo de la Catedral de Mondoñedo (871-1492). Lugo: Diputación Provincial de Lugo, 79.

16 Cal Pardo, Mondoñedo -Catedral, Ciudad, Obispado-, 791.

17 A.C.M., Fundaciones Antiguas, arm. 3 , est. 1 , leg. $1,17 v-18 r, 34 r, 77 r$, $87 r-115 r$.

${ }^{18}$ A.C.M., Miscelánea, arm. 4, est. 1, leg. 2, n. ${ }^{\circ}$, s.f.

19 A.C.M., Documentos Sueltos, arm. 7, est. 4, leg. 1, n. ${ }^{\circ}$ 92, s.f.

20 A.C.M., Protocolos Notariales, arm. 2, est. 2, leg. 2, n. ${ }^{\circ} 18,133 r-$ $134 \mathrm{r}$.

21 A.C.M., Actas Capitulares, vol. $8,77 \mathrm{r}$.

22 A.C.M., Actas Capitulares, vol. 8, 84r; A.C.M., Protocolos Notariales, arm. 2 , est. 2 , leg. 3, n. $^{\circ} 21,10 \mathrm{r}-11 \mathrm{v}$. 
23 A.C.M., Actas Capitulares, vol. $8,85 \mathrm{v}$.

24 A.C.M., Protocolos Notariales, arm. 2, est. 2, leg. 3, n. ${ }^{\circ} 21,73 r$; A.C.M., Actas Capitulares, vol. 8, 92v. Carrero Santamaría afirma que la idea de construir la girola ya era un hecho en 1596, y basa su interpretación en un contrato de julio de aquel año relacionado con la renovación de la madera en la crujía septentrional del claustro, Carrero Santamaría, Las catedrales de Galicia, 167. A juicio personal, aquella obra en absoluto tiene que ver con la nueva cabecera. Que entonces se extraiga "la losa de manera que no se pierda" no implica su reutilización en la girola dos años después, A.C.M., Protocolos Notariales, arm. 2 , est. 2 , leg. $3, \mathrm{n}^{\circ} 22,158 \mathrm{r}$ $-160 \mathrm{v}$.

25 El prelado era natural del lugar de Susilla, perteneciente entonces a la Merindad de Campoo y hoy día al municipio cántabro de Valderredible, A.H.P.L., Protocolos Notariales, Ribadeo, Jácome Rodríguez de Labrada, leg. 1743-8, 26r - 26v. De la misma localidad provenía su primo Juan Gutiérrez de Torices, arcediano de Montenegro en dicha catedral durante su episcopado. Su parentesco se reseña en el testamento del canónigo de 1625, A.H.P.L., Protocolos Notariales, Mondoñedo, Domingo Rodríguez Bermúdez, leg. 8376-1, 144r. El epitafio del obispo en la catedral de Oviedo también indica su lugar de procedencia. Cal Pardo ya sospechaba que entre el pontífice y el prebendado existía algún vínculo parental, Cal Pardo, "Episcopologio mindoniense. Siglo XVI," 269-270; Cal Pardo, Episcopologio mindoniense, 384.

26 A.C.M., Protocolos Notariales, arm. 2, est. 2, leg. 3, n. ${ }^{\circ} 21,73 r$ - 73v. Esta apreciación conviene recalcarla porque muchos autores creyeron erróneamente que en un inicio estaba previsto realizar doce capillas y que finalmente se realizaron las cuatro que cierran el testero.

27 A.C.M., Protocolos Notariales, arm. 2 , est. 2 , leg. $3, n{ }^{\circ} 21,73 r-73 v$, $75 r$. Conviene señalar que los primeros tramos de las naves paralelas del deambulatorio presentan sendos arcos abiertos a la capilla mayor. Estos se perforaron a partir de 1719, A.C.M., Actas
Capitulares, vol. 16, 185v; Cal Pardo, Enrique. 2001. "Episcopologio mindoniense. Primera mitad del siglo XVIII." Estudios Mindonienses 17: 296; Cal Pardo, La Catedral de Mondoñedo, 41; Cal Pardo, Episcopologio mindoniense, 674.

28 A.C.M., Actas Capitulares, vol. 8, 108r. Desde finales de septiembre Alonso de Cartas pasó a ocupar el cargo de canónigo fabriquero tras el fallecimiento de Pedro de Montalvo, A.C.M., Actas Capitulares, vol. 8, 104v.

29 A.C.M., Actas Capitulares, vol. 8, 108r; A.C.M., Protocolos Notariales, arm. 2, est. 2, leg. 3, n. ${ }^{\circ} 21,206 r-$ $207 v$.

30 Vid. nota 25.

31 A.M.M., carp. 923, Libro de Actas (1595-1608), 81v - 82r, 243v; A.C.M., Actas Capitulares, vol. 8, 93v - 94r, 100r-100v, 104v; A.C.M., Protocolos Notariales, arm. 2, est. 2, leg. 3, n. ${ }^{\circ} 21,92 r-95 r, 161 r-163 v$. Conste que el letrero alusivo a la fundación, muy revelador por otra parte, no reseña que se hiciese en 2.000 escudos de oro, sino en 2.000 ducados. Dicha piedra se colocó finalmente en la capilla en 1612 y rezaba lo siguiente: "hesta capilla hes de nycolas beche y de maria de losada su muger $y$ de antolin de estrada su segundo marido hesta dotada en una misa perpetua dio dos myll ducados para la obra de este trascoro dexo el pan de la alhondiga a los pobres desta çiudad caso quarenta huerfanas dio qurea myll mrs a los pobres de villafranca hiço otras muchas limosnas en esta çiudad y otras partes el ano de el hambre", A.C.M., Actas Capitulares, vol. 9, 386r - 386v. Por otro lado, el que se reaprovechase la reja de la capilla medieval es lógico dada su contemporaneidad, pues en 1589 el obispo Isidro Caja de Lajara había ordenado hacerla conforme "al modo y traça de la de la capilla de sanctiago", A.C.M., Miscelánea, arm. 4, est. 1, leg. 2, n. ${ }^{\circ} 6$, s.f.

32 A.C.M., Actas Capitulares, vol. 10, $53 v-54 r, 57 v-58 r$, 95r; A.C.M., arm. 3, est. 1, leg. 4, 42r-46v; A.H.P.L., Protocolos Notariales, Mondoñedo, Juan Abad, leg. 7211-2, 52r - 57v, 269r - 270r; Cal Pardo, "Episcopologio mindoniense. Siglo XVII," 48; Cal Pardo, Episcopologio mindoniense, 434;
Fernández Castiñeiras, Enrique, y Monterroso Montero, Juan Manuel. 2006. A pintura mural nas catedrais galegas. Séculos XVI-XVIII. Santiago de Compostela: Tórculo, 156.

33 "yten es condiçion que a de derrocar a su costa todo lo que fuere menester deshaçersse como hes la sacrestia y $p^{\text {te }}$ de la capilla de la madalena $y$ todo lo demas nesçessario que se ubiere de derribar y deshaçersse $p^{\text {a }}$ haçerse la dha obra [...] yten que a de rredificar ansi mesmo a su costa la capilla de la madalena reparando lo que de ella se derivare y haçiendo un arco nuevo", A.C.M., Protocolos Notariales, arm. 2, est. 2 , leg. 3, n. $^{\circ} 21,74 \mathrm{v}$.

${ }^{34}$ Sobre esta reja véase Gallego de Miguel, Amelia. 1963. El arte del hierro en Galicia. Madrid: CSIC, 86-87; Cal Pardo, "Historia del pontificado," 416; Cal Pardo, Mondoñedo -Catedral, Ciudad, Obispado-, 80; Cal Pardo, "Episcopologio mindoniense. Siglo XVI," 190; Cal Pardo, La Catedral de Mondoñedo, 22-24; Cal Pardo, Episcopologio mindoniense, 311.

35 A.C.M., Cuentas de la Fábrica, vol. 28/2, 242v.

36 "otrosi hes condion que a de abrir la puerta $p^{a}$ la capilla de san ju $y$ aderezar la capilla $p^{\text {a }}$ las reliqas y abiendo alli ynconbenyente ha de azer otra tanta obra anadiendo a la capilla que se aze junto a la de santo", A.C.M., Protocolos Notariales, arm. 2, est. 2, leg. 3, n. ${ }^{\circ} 21,75 \mathrm{v}$.

37 Dicha reliquia provino del monasterio de Celanova, A.C.M., arm. 3, Memorias para la historia de la Santa Yglesia de Mondoñedo, 107r (1. ${ }^{\text {a folia- }}$ ción); Cal Pardo, "Episcopologio mindoniense. Siglo XVII," 45-46; Cal Pardo, Episcopologio mindoniense, 431-432.

38 A.C.M., Actas Capitulares, vol. 8, 107r; A.C.M., Protocolos Notariales, arm. 2 , est. 2 , leg. $3, n .^{\circ} 21,11 \mathrm{r}-11 \mathrm{v}$, $186 r-187 r$

39 Muchos de ellos de carácter ordinario, A.C.M., Actas Capitulares, vol. $8,121 \mathrm{v}, 130 \mathrm{v}, 133 \mathrm{r}, 135 \mathrm{r}, 157 \mathrm{v}, 169 \mathrm{v}$, 179v, 188r, 220r, 230r.

40 Pérez Costanti, Diccionario de artistas, 577; Rodríguez Fernández, Carlos. 1987. "Estudio artístico de la iglesia y monasterio de San Vicente del Pino de Monforte de Lemos." Boletín 
do Museo Provincial de Lugo 3: 76; Goy Diz, Ana. 2009. "Nuevos datos sobre el monasterio de San Vicente del Pino de Monforte de Lemos." en Galicia monástica. Estudos en lembranza da profesora María José Portela Silva, ed. por José Miguel Andrade Cernadas, Raquel Casal García, Roberto Javier López López, 524. Santiago de Compostela: Universidade de Santiago de Compostela. Los lazos familiares entre Morlote y Juan de la Sierra los aporta Cagigas Aberasturi, Ana Isabel. 2015. "Los maestros canteros de Trasmiera." Tesis Doctoral inédita, Universidad de Cantabria, 66, 582.

41 A.C.M., Actas Capitulares, vol. $8,122 r$.

42 A.C.M., Actas Capitulares, vol. $8,126 r$.

43 A.H.P.L., Protocolos Notariales, Mondoñedo, Francisco Núñez de Callobre, leg. 7009-3, 152r.

44 A.H.P.L., Protocolos Notariales, Mondoñedo, Francisco Núñez de Callobre, leg. 7009-3, 153r.

45 A.C.M., Actas Capitulares, vol. $8,141 \mathrm{v}$.

${ }^{46}$ A.C.M., Actas Capitulares, vol. $8,144 \mathrm{v}, 158 \mathrm{v}$

47 A.C.M., Documentos Sueltos, arm. 9, est. 1, leg. 8, n 5/2, s.f.

48 A.C.M., Actas Capitulares, vol. 8,177 r. Ya el contrato indica que la piedra habría de extraerse de las cercanas canteras de "texosso". El trabajo de su corte y desbasto se haría a costa de Morlote, así como lo correspondiente a las cimbras y andamiaje; mientras que el acarreo de los materiales se pagaría directamente con los fondos de la fábrica catedralicia, A.C.M., Protocolos Notariales, arm. 2, est. 2, leg. 3, n. ${ }^{\circ} 21$, $73 v-74 r$. El monte de Toxoso se halla cerca de Mondoñedo y se inscribe hoy día en el término municipal de Abadín.

49 Esto lo suponemos porque en 1611 se comisionó a un canónigo para que se encargase de "demarcary amoxonar la juron del coto de baronçeIle", A.C.M., Actas Capitulares, vol. 9, $330 \mathrm{r}-330 \mathrm{v}$

50 A.C.M., Actas Capitulares, vol. 8, 206v.

51 A.C.M., Actas Capitulares, vol. $8,212 v-213 r$.
52 A.C.M., Protocolos Notariales, arm. 2, est. 2, leg. $3, n{ }^{\circ} 26,18 r-19 \mathrm{v}$.

53 A.C.M., Actas Capitulares, vol. $8,233 v$.

54 A.C.M., Actas Capitulares, vol. $8,227 \mathrm{v}$.

55 A.C.M., Actas Capitulares, vol. $8,233 v-234 r, 235 v$.

${ }^{56}$ La reseña en 1763 el canónigo Francisco Antonio Villaamil y Savedra, A.C.M., arm. 3, Memorias para la historia de la Santa Yglesia de Mondoñedo, 105v (1. a foliación).

57 A.C.M., Actas Capitulares, vol. $8,255 \mathrm{v}$

58 Nos lo hace suponer esta vaga referencia: "Mandaron dar libranza a luis fre [Fernández] de siete rres de la rexa", A.C.M., Actas Capitulares, vol. 8, 258 .

59 A.C.M., Protocolos Notariales, arm. 2, est. 2, leg. $4, n^{\circ} 27,36 r-37 v$.

${ }^{60}$ Así consta en la visita pastoral girada por el obispo Samaniego, A.C.M., arm. 3, n. $^{\circ} 41,1$ r.

61 Domínguez Ortiz, Antonio. 1970. La sociedad española en el siglo XVII. El estamento eclesiástico. Madrid: CSIC, 268-269; Pérez López, Segundo Leonardo. 1985. "Las primeras «Relationes ad limina» de la Diócesis de Mondoñedo." Estudios Mindonienses 1: $92-93$.

62 A.H.P.L., Protocolos Notariales, Mondoñedo, Juan Abad, leg. 7210-4, $62 r-63 r$

63 A.C.M., Protocolos Notariales, arm. 2, est. 2, leg. 3, n. ${ }^{\circ} 26,4 r-10 r$.

64 A.C.M., Actas Capitulares, vol. 8, 243r; ídem, Protocolos Notariales, arm. 2, est. 2, leg. 3, n. ${ }^{\circ} 22,192 r-$ $193 r$.

65 A.C.M., Actas Capitulares, vol. $8,271 v, 272 v-273 r$.

66 A.C.M., Actas Capitulares, vol. 8, 188r; A.C.M., Protocolos Notariales, arm. 2, est. 2, leg. 3, n. $^{\circ} 22,79 r-80 v$; A.C.M., Protocolos Notariales, arm. 2, est. 2 , leg. 3, n. $^{\circ} 25,80$ r.

67 Entre los distintos documentos que indican su vecindad, destacamos A.C.M., Protocolos Notariales, arm. 2, est. 2, leg. 3, $n^{\circ} 21,73$ r. El pionero en ofrecer noticias suyas fue Pérez Costanti, Diccionario de artistas, 397,
585-586, cuyos datos reiteró Sojo y Lomba, Fermín de. 1935. Los Maestros Canteros de Trasmiera. Madrid: Huelves y Compañía, 109. Dentro de la abundante bibliografía referente a la actividad de los trasmeranos en Galicia, aparte de estas dos obras, conviene conocer: Bonet Correa, Antonio. 1966. La arquitectura en Galicia durante el siglo XVII. Madrid: CSIC; Alonso Ruiz, Begoña, Aramburu-Zabala Higuera, Miguel Ángel, González Echegaray, María del Carmen, y Polo Sánchez, Julio Juan. 1991. Artistas cántabros de la Edad Moderna. Su aportación al arte hispánico (diccionario biográfico-artístico). Santander: Universidad de Cantabria; Alonso Ruiz, Begoña. 1992. El arte de la cantería. Los maestros trasmeranos de la Junta de Voto. Santander: Universidad de Cantabria; Goy Diz, Ana. 1993. "Los trasmeranos en Galicia: la familia de los Arce." en Juan de Herrera y su influencia. Actas del Simposio. Camargo, 14-17 julio 1992, dir. por Miguel Ángel Aramburu-Zabala Higuera, coord. por Javier Martínez Gómez, 147-163. Santander: Fundación Obra Pía Juan de Herrera, Universidad de Cantabria; Dúo Rámila, Diana. 2011. "Maestros canteros de Trasmiera en Galicia (siglo XVI)." Espacio, Tiempo y Forma. Serie VII, Historia del Arte 24: 81-100; Cagigas Aberasturi, Ana Isabel, Los maestros canteros de Trasmiera.

68 Cagigas Aberasturi, Ana Isabel, Los maestros canteros de Trasmiera, 66, 582. La noticia acerca de la muerte de Morlote indica que le sobrevivieron dos hijos legítimos con María de la Sierra: Pedro y María de Morlote. Dichos datos se extraen del Archivo Histórico Diocesano de Santander, Fondo Parroquial de San Juan Bautista de Secadura, leg. 2, fol. 156r, y me fueron proporcionados de forma altruista por José F. Gutiérrez Morlote, a quien agradezco su generosidad.

69 Sojo y Lomba, Los maestros canteros de Trasmiera, 108-109; Alonso Ruiz y Aramburu-Zabala Higuera et. al., Artistas cántabros de la Edad Moderna, 441.

${ }^{70}$ La presencia de Morlote en Meira en 1588 se reseña en el Archivo Histórico Nacional, Clero Secular Regular, leg. 6447, 263v - 264r (323v - 324r), dato que me fue proporcionado desin- 
teresadamente por Fernando Villapol, a quien agradezco su gesto. Produce gran desconcierto que en 1640 el supuesto hijo del Pedro de Morlote fallecido en 1621 en Mondoñedo -pues se declara vástago de Pedro de Morlote y de María de la Sierra, vecinos de Secadura- diga que su abuelo era Juan Gómez de Morlote y su bisabuelo Pedro Gómez de Morlote, Archivo de la Real Chancillería de Valladolid, Registro de Ejecutorias, caja 2706-66, s.f. En cuanto al resto de información vid. Pérez Costanti, Diccionario de artistas, 167, 514, 529, 585-586; Cotarelo Valledor, Armando. 1945-1946. El cardenal Don Rodrigo de Castro y su fundación en Monforte de Lemos. Madrid: Magisterio Español, vol. 1, 297-303, 305, 310, y vol. 2, 86, 123, 264-292; Lorenzana Lamelo, María Luísa. 1989. Aportación documental al estudio histórico-artístico de dos fundaciones monfortinas: el Colegio de la Compañía y el convento de las clarisas. Lugo: Diputación Provincial, 53-59; Rivera Vázquez, Evaristo. 1989. Galicia y los jesuitas. Sus colegios y enseñanza en los siglos XVI al XVIII. La Coruña: Fundación Barrié de la Maza, 569, 570-573; Pérez Rodríguez, Fernando. 1995. "Algunas consideraciones sobre la construcción del Colegio de Nuestra Señora de la Antigua de Monforte de Lemos (Lugo), 1592-1619." en Monjes y Monasterios Españoles. Arte, Arquitectura, Restauraciones, Iconografía, Música, Hospitales y Enfermerías, Medicina, Farmacia, Mecenazgo, Estudiantes. Actas del Simposium (1/5-IX-1995), ed. por Francisco Javier Campos y Fernández de Sevilla, 501, 503, 508-510. San Lorenzo del Escorial: Estudios Superiores del Escorial, R.C.U. "Escorial-M. ${ }^{\text {a Cristina"; }}$ Martínez González, Esteban. 2000. Colegio Ntra. Sra. de la Antigua (Monforte de Lemos). León: Everest, 14, 23.

71 Vid. nota 40.

72 Bonet Correa, Antonio. 2001. "El Colegio del Cardenal y el clasicismo." en Xornadas sobre o cardeal Rodrigo de Castro. Actas das xornadas realizadas pola Dirección Xeral de Promoción Cultural en Monforte de Lemos os días 5 e 6 de outubro de 2000, 116. Santiago de Compostela: Xunta de Galicia.

${ }^{73}$ Su singularidad tipológica ya la destacaron autores como Yzquierdo
Perrín, Ramón. 1985. "La arquitectura románica cisterciense." Galicia Arte, ed. por Francisco Rodríguez Iglesias, vol. 12, 59. A Coruña: Hércules; Yzquierdo Perrín, "Las Catedrales de la Diócesis," 141; San Cristóbal Sebastián, "IV centenario de la ampliación," 48. Por aquel entonces la catedral de Sevilla ya contaba con un deambulatorio recto, y Andrés de Vandelvira había diseñado otro para la catedral de Jaén en la década de 1550. Pero establecer nexos de unión con esta última puede resultar resbaladizo e infructuoso, pues sufrió diversas alteraciones y sus fases constructivas se postergaron largamente en el tiempo. Sobre la catedral giennense vid. fundamentalmente: Higueras Maldonado, Juan. 2009. La catedral de Jaén. Su construcción renacentista (S. XVII-XVIII). Jaén: Universidad de Jaén; Galera Andreu, Pedro. 2009. La Catedral de Jaén. Barcelona-Madrid: Lunwerg.

${ }^{74}$ Chueca Goitia, Fernando. 1947. La catedral de Valladolid. Una página del Siglo de Oro de la arquitectura española, Madrid: CSIC, 39-40; Bustamante García, Agustín. 1983. La arquitectura clasicista del foco vallisoletano (15611640).Valladolid: Institución Cultural Simancas, 121; Navascués Palacio, Pedro. 1998. Teoría del coro en las catedrales españolas. Madrid: Real Academia de Bellas Artes de San Fernando, 76-77.

75 Rodríguez y Gutiérrez de Ceballos, Alfonso. 1991. "Liturgia y configuración del espacio en la arquitectura española y portuguesa a partir del Concilio de Trento." Anuario del Departamento de Historia y Teoría del Arte 3: 46-48; Rodríguez y Gutiérrez de Ceballos, Alfonso. 1993. "La arquitectura religiosa de Juan de Herrera y la Contrarreforma." en Juan de Herrera y su influencia. Actas del Simposio. Camargo, 14-17 julio 1992, dir. por Miguel Ángel Aramburu-Zabala Higuera, coord. por Javier Martínez Gómez, 197, 200. Santander: Fundación Obra Pía Juan de Herrera, Universidad de Cantabria; Rodríguez y Gutiérrez de Ceballos, Alfonso. 2003. "Gótico versus Clásico: el principio de uniformidad de estilo en la construcción de la catedral nueva de Salamanca." en El comportamiento de las catedrales españolas. Del Barroco a los Historicismos, ed. por Germán Ramallo Asensio, 17. Murcia: Universidad de Murcia, Consejería de Educación y Cultura, Fundación Cajamurcia.

76 Vila Jato, María Dolores. 1998. "Los espacios construidos en tiempos de Felipe II." en El Reino de Galicia en la monarquía de Felipe II, coord. por Antonio Eiras Roel, 510-511. Santiago de Compostela: Xunta de Galicia; Vila Jato, María Dolores. 1999. "La actividad artística en la provincia de Mondoñedo durante el Renacimiento." Estudios Mindonienses 15: 466-467. Andrés Rosende fue más allá y consideró esta obra una intervención en estilo, presidida "por el deseo de no violentar la tradición", resultando "una de las primeras actuaciones historicistas que se hayan llevado a cabo en Galicia [...] con un firme propósito de neomedievalismo", Rosende Valdés, Andrés A. 2001. "La modificación de las tipologías tradicionales en el mundo moderno: la ampliación y reforma de las catedrales gallegas." en Las catedrales españolas en la Edad Moderna. Aproximación a un nuevo concepto del espacio sagrado, ed. por Miguel Ángel Castillo Oreja, 64. Madrid: Fundación BBVA, A. Machado Libros. Por su parte, Paz Míguez, sin fundamento alguno, defiende que esta obra y su consonancia estilística con la fábrica anterior responden a una imposición de Gutiérrez Mantilla justificada en la admiración que le despertaba la catedral de Santiago de Compostela, Paz Míguez, María. 2006. "Catedrais de Lugo e Mondoñedo." en Artistas galegos arquitectos. O Renacemento, ed. por Carlos del Pulgar Sabín, 67. Vigo: Nova Galicia.

77 Rodríguez y Gutiérrez de Ceballos, "Gótico versus Clásico," 16.

78 Lampérez y Romea, Vicente. 1909. Historia de la arquitectura cristiana española en la Edad Media según el estudio de los Elementos y los Monumentos. Madrid, vol. 2, 450; el claustro meirego, al igual que la gran mayoría de las dependencias abaciales, desapareció a lo largo de los siglos XIX y XX. Sobre esta cuestión véase Barral Rivadulla, María Dolores. 2002. "El monasterio de Santa María de Meira. Crónica de la desaparición y recuperación de una fábrica.", en Estudios sobre patrimonio artístico. Homenaje del departamento de Historia del Arte y de la Facultad de Geografía e Historia de la Universidad 
de Santiago de Compostela a la Prof. Dra. Ma del Socorro Ortega Romero, coord. por María Dolores Barral RivaduIla, José Manuel López Vázquez, 611 626. Santiago de Compostela: Xunta de Galicia; Vila Jato, "La actividad artística en la provincia de Mondoñedo," 467.

79 "yten es condiçion que los cruzeros y nabes destas treze capillas an de ser de piedra de grano de texosso buena piedra y bien labrada y no aber de llebar cada capilla mas de una nabe y un cruzero sin formas // y si se echaren las dhas formas se an de pagar por demasia", A.C.M., arm. 2, est. 2, leg. 3, n. ${ }^{\circ} 21,74$ r.

${ }^{80}$ Acerca de este escudo, véase Cal Pardo, "Episcopologio Mindoniense. Siglo XVI," 197, 202, 212; Cal Pardo, Episcopologio Mindoniense, 317, 322, 332; Rúa Veloso, Olalla. 2005. Heráldica del Municipio de Mondoñedo. Lugo: Diputación Provincial de Lugo, 25-27. Santos San Cristóbal, por su parte, lo considera un símbolo del Cabildo mindoniense, San Cristóbal Sebastián, Santos. 1989. La Catedral de Mondoñedo. Lugo: Diputación Provincial de Lugo, 58.

${ }^{81}$ Cal Pardo, "Episcopologio Mindoniense. Siglo XVI," 269; Cal Pardo, Episcopologio Mindoniense, 384.
82 Losada Varela, Celestina. 2007. La arquitectura en el otoño del Renacimiento. Juan de Naveda (1590-1638). Santander: Universidad de Cantabria, 288 y ss. Aparte de Mondoñedo y Oviedo, hubo otras catedrales españolas cuyas cabeceras se vieron ampliadas con sus respectivas girolas entre fines del siglo XVI y principios del XVII. Es el caso de Calahorra, Sigüenza u Ourense, Ramallo Asensio, Germán. 2003. "Aspectos generales de las catedrales españolas en el Barroco y su proyección al siglo XIX." en Las catedrales españolas. Del Barroco a los Historicismos, ed. por Germán Ramallo Asensio, 19. Murcia: Universidad de Murcia. En todas ellas, salvo en la mindoniense, se apostó por el clásico deambulatorio semicircular.

83 A.H.P.L., Protocolos Notariales, Mondoñedo, Francisco Núñez de Callobre, leg. 7009-3, 152r.

84 En 1643 había un Domingo de Fiallega avecindado en el lugar de Mourelle -perteneciente a la parroquia de Santa María de Bretoña, A Pastoriza, Lugo-, pero ignoramos si se trata del mismo personaje, ídem, Protocolos Notariales, Mondoñedo, Marcos Fernández de Luaces, leg. 7029-3, 25r-25v.

85 A.C.M., Protocolos Notariales, arm. 2, est. 2, leg. $4, n .^{\circ} 27,36 r$.
86 A.M.M., carp. 923, Libro de Actas (1595-1608), 221r, 223v, 248r 249r, 270r.

87 Pérez Costanti, Diccionario de artistas, 91-92.

88 A.H.P.L., Protocolos Notariales, Mondoñedo, Juan Abad, leg. 7210-2, $36 r-37 r$.

89 Pérez Costanti, Diccionario de artistas, 166-167, 578; Cotarelo Valledor, El cardenal Don Rodrigo de Castro, vol. 1, 307-308, y vol. 2, 122, 309-323; Lorenzana Lamelo, Aportación documental al estudio histórico-artístico de dos fundaciones monfortinas, 60-61, 64; Rivera Vázquez, Galicia y los jesuitas, 569, 572-574; Pérez Rodríguez, "Algunas consideraciones sobre la construcción del Colegio," 503-521; Martínez González, Colegio Ntra. Sra., 14, 22-23.

90 Cotarelo Valledor, El cardenal Don Rodrigo de Castro, vol. 1, 305; Pérez Rodríguez, "Algunas consideraciones sobre la construcción del Colegio," 503.

91 A.H.P.L., Protocolos Notariales, Mondoñedo, Bartolomé Arias Maseda y Baamonde, leg. 7006-4, 87r-87v. 


\section{REFERENCIAS}

Alonso Ruiz, Begoña. 1992. El arte de la cantería. Los maestros trasmeranos de la Junta de Voto. Santander: Universidad de Cantabria.

Alonso Ruiz, Begoña, Aramburu-Zabala Higuera, Miguel Ángel, González Echegaray, María del Carmen, y Polo Sánchez, Julio Juan. 1991. Artistas cántabros de la Edad Moderna. Su aportación al arte hispánico (diccionario biográfico-artístico). Santander: Universidad de Cantabria.

Barral Rivadulla, María Dolores. 2002. "El monasterio de Santa María de Meira. Crónica de la desaparición y recuperación de una fábrica." , In Estudios sobre patrimonio artístico. Homenaje del departamento de Historia del Arte y de la Facultad de Geografía e Historia de la Universidad de Santiago de Compostela a la Prof. Dra. Ma del Socorro Ortega Romero, edited by María Dolores Barral Rivadulla, José Manuel López Vázquez, 611-626. Santiago de Compostela: Xunta de Galicia.

Bonet Correa, Antonio. 1966. La arquitectura en Galicia durante el siglo XVII. Madrid: CSIC.

Bonet Correa, Antonio. 2001. "El Colegio del Cardenal y el clasicismo." In Xornadas sobre o cardeal Rodrigo de Castro. Actas das xornadas realizadas pola Dirección Xeral de Promoción Cultural en Monforte de Lemos os días 5 e 6 de outubro de 2000, 115-120. Santiago de Compostela: Xunta de Galicia.

Bustamante García, Agustín. 1983. La arquitectura clasicista del foco vallisoletano (1561-1640). Valladolid: Institución Cultural Simancas.

Cagigas Aberasturi, Ana Isabel. 2015. "Los maestros canteros de Trasmiera." Tesis Doctoral inédita, Universidad de Cantabria.

Cal Pardo, Enrique. 1987. "Sacristía y Custodia de la Catedral Basílica de Mondoñedo." Estudios Mindonienses 3: 549-570.

Cal Pardo, Enrique. 1988. "Historia del pontificado de D. Diego de Soto." Estudios Mindonienses 4: 339-437.

Cal Pardo, Enrique. 1990. Catálogo de los documentos medievales, escritos en pergamino, del
Archivo de la Catedral de Mondoñedo (8711492). Lugo: Diputación Provincial de Lugo.

Cal Pardo, Enrique. 1992. Mondoñedo-Catedral, Ciudad, Obispado- en el siglo XVI. Catálogo de la documentación del Archivo Catedralicio. Santiago de Compostela: Xunta de Galicia.

Cal Pardo, Enrique. 1999. "Episcopologio mindoniense. Siglo XVI." Estudios Mindonienses 15: $125-286$.

Cal Pardo, Enrique. 2000. "Episcopologio mindoniense. Siglo XVII." Estudios Mindonienses 16: 13-291.

Cal Pardo, Enrique. 2001. "Episcopologio mindoniense. Primera mitad del siglo XVIII." Estudios Mindonienses 17: 277-422.

Cal Pardo, Enrique. 2002. La Catedral de Mondoñedo. Historia. Lugo.

Cal Pardo, Enrique. 2003. Episcopologio mindoniense. Santiago de Compostela: CSIC-Xunta de Galicia, Instituto de Estudios Gallegos "Padre Sarmiento", Mondoñedo-Ferrol: Estudios Mindonienses.

Carrero Santamaría, Eduardo. 1999. "De la influencia cisterciense en Santa María de Mondoñedo a la evolución arquitectónica de un proyecto basilical románico." In Actas. // Congreso Internacional sobre el Císter en Galicia y Portugal, vol. 3, 1165-1186. Ourense: Deputación Ourense, Abadías Cistercienses de Galicia, Asturias y León, Concello de Ourense, Caixa Ourense, Santiago de Compostela: Xunta de Galicia.

Carrero Santamaría, Eduardo. 2005. Las catedrales de Galicia durante la Edad Media. Claustros y entorno urbano. A Coruña: Fundación Pedro Barrié de la Maza.

Carro García, Jesús. 1950. Las catedrales gallegas. Buenos Aires: Galicia.

Castro Fernández, Belén. 2007. "Francisco PonsSorolla y Arnau, arquitecto-restaurador: sus intervenciones en Galicia (1945-1985)." Tesis Doctoral inédita, Universidade de Santiago de Compostela, vol. 2.

Castro Fernández, Celia. 1993. Estudio iconográfico y estilístico de los capiteles de la catedral 
de Mondoñedo. Lugo: Diputación Provincial de Lugo.

Chueca Goitia, Fernando. 1947. La catedral de Valladolid. Una página del Siglo de Oro de la arquitectura española, Madrid: CSIC.

Cotarelo Valledor, Armando. 1945-1946. El cardenal Don Rodrigo de Castro y su fundación en Monforte de Lemos. Madrid: Magisterio Español, vols. 1-2.

Díaz Tie, Marta. 1999. “La catedral medieval de Mondoñedo: arquitectura, escultura y pintura monumental." Estudios Mindonienses 15: 343-373.

Domínguez Ortiz, Antonio. 1970. La sociedad española en el siglo XVII. El estamento eclesiástico. Madrid: CSIC.

Dúo Rámila, Diana. 2011. "Maestros canteros de Trasmiera en Galicia (siglo XVI)." Espacio, Tiempo y Forma. Serie VII, Historia del Arte 24: 81-100. https://doi.org/10.5944/etfvii.24.2011.1402

Fernández Castiñeiras, Enrique, and Juan Manuel Monterroso Montero. 2006. A pintura mural nas catedrais galegas. Séculos XVI-XVIII. Santiago de Compostela: Tórculo.

Galera Andreu, Pedro. 2009. La Catedral de Jaén. Barcelona-Madrid: Lunwerg.

Gallego de Miguel, Amelia. 1963. El arte del hierro en Galicia. Madrid: CSIC.

García Lamas, Manuel Antonio. 2015. “Ubicación y fisionomía de cabildos y audiencias públicas en la catedral de Mondoñedo (siglos XIII-XV)." Estudios Mindonienses 30: 391-436.

García Oro, José, and María José Portela Silva. 2005. "A peste, fame et bello, libera nos Domine. Galicia y la peste en el reinado de Felipe II." Semata 17: 231-258.

Goy Diz, Ana. 1993. "Los trasmeranos en Galicia: la familia de los Arce." In Juan de Herrera y su influencia. Actas del Simposio. Camargo, 14-17 julio 1992, dir. Miguel Ángel AramburuZabala Higuera, coord. Javier Martínez Gómez, 147-163. Santander: Fundación Obra Pía Juan de Herrera, Universidad de Cantabria.
Goy Diz, Ana. 2009. "Nuevos datos sobre el monasterio de San Vicente del Pino de Monforte de Lemos." In Galicia monástica. Estudos en lembranza da profesora María José Portela Silva, edited by José Miguel Andrade Cernadas, Raquel Casal García, Roberto Javier López López, 517-535. Santiago de Compostela: Universidade de Santiago de Compostela.

Higueras Maldonado, Juan. 2009. La catedral de Jaén. Su construcción renacentista (S. XVIIXVIII). Jaén: Universidad de Jaén.

Lampérez y Romea, Vicente. 1909. Historia de la arquitectura cristiana española en la Edad Media según el estudio de los Elementos y los Monumentos. Madrid, vol. 2.

Lorenzana Lamelo, María Luísa. 1989. Aportación documental al estudio histórico-artístico de dos fundaciones monfortinas: el Colegio de la Compañía y el convento de las clarisas. Lugo: Diputación Provincial.

Losada Varela, Celestina. 2007. La arquitectura en el otoño del Renacimiento. Juan de Naveda (1590-1638). Santander: Universidad de Cantabria.

Martínez González, Esteban. 2000. Colegio Ntra. Sra. de la Antigua (Monforte de Lemos). León: Everest.

Murguía, Manuel. 1888. Galicia, Barcelona: Daniel Cortezo y C.A.

Navascués Palacio, Pedro. 1998. Teoría del coro en las catedrales españolas. Madrid: Real Academia de Bellas Artes de San Fernando.

Nogueira Santiago, Paulo. 2004. “Las epidemias de peste de 1598 y 1599 en Galicia: el ejemplo de la villa de Noia." In Ano Santo Camiño da Xuventude. Mostra Filatélica Xuvenil Nacional. Noia, do 23 de xullo ao 1 de agosto do 2004, 69-77. Noia: Grupo Filatélico e Numismático de Noia.

Núñez-Varela y Lendoiro, José Raimundo. 1998. La peste de 1598 en Betanzos de los Caballeros. Ciento y un días de angustia y devoción. Betanzos: Ayuntamiento de Betanzos.

Paz Míguez, María. 2006. "Catedrais de Lugo e Mondoñedo." In Artistas galegos arquitectos. 
O Renacemento, ed. por Carlos del Pulgar Sabín, 64-103. Vigo: Nova Galicia.

Pérez Costanti, Pablo. 1930. Diccionario de artistas que florecieron en Galicia durante los siglos XVI y XVII. Santiago: Seminario C. Central.

Pérez López, Segundo Leonardo. 1985. “Las primeras «Relationes ad limina» de la Diócesis de Mondoñedo." Estudios Mindonienses 1: 83-103.

Pérez Rodríguez, Fernando. 1995. "Algunas consideraciones sobre la construcción del Colegio de Nuestra Señora de la Antigua de Monforte de Lemos (Lugo), 1592-1619." In Monjes y Monasterios Españoles. Arte, Arquitectura, Restauraciones, Iconografía, Música, Hospitales y Enfermerías, Medicina, Farmacia, Mecenazgo, Estudiantes. Actas del Simposium (1/5IX-1995), edited by Francisco Javier Campos y Fernández de Sevilla, 497-521. San Lorenzo del Escorial: Estudios Superiores del Escorial, R.C.U. "Escorial-M. ${ }^{\text {a Cristina". }}$

Pérez Rodríguez, Fernando. 2000. "O Renacemento." In Fontes escritas para a historia da arquitectura e do urbanismo en Galicia (Séculos XI-XX), coord. Alfredo Vigo Trasancos, vol. 1. Santiago de Compostela: Xunta de Galicia.

Ramallo Asensio, Germán. 2003. "Aspectos generales de las catedrales españolas en el Barroco y su proyección al siglo XIX." In Las catedrales españolas. Del Barroco a los Historicismos, edited by Germán Ramallo Asensio, 11-40. Murcia: Universidad de Murcia.

Rivas Carmona, Jesús. 1994. Los trascoros de las catedrales españolas: estudio de una tipología arquitectónica. Murcia: Universidad de Murcia.

Rivera Vázquez, Evaristo. 1989. Galicia y los jesuitas. Sus colegios y enseñanza en los siglos XVI al XVIII. La Coruña: Fundación Barrié de la Maza.

Rodríguez Fernández, Carlos. 1987. "Estudio artístico de la iglesia y monasterio de San Vicente del Pino de Monforte de Lemos." Boletín do Museo Provincial de Lugo 3: 69-85.

Rodríguez y Gutiérrez de Ceballos, Alfonso. 1991. "Liturgia y configuración del espacio en la arquitectura española y portuguesa a partir del Concilio de Trento." Anuario del Departamento de Historia y Teoría del Arte 3: 43-52.

Rodríguez y Gutiérrez de Ceballos, Alfonso. 1993.

"La arquitectura religiosa de Juan de Herrera y la Contrarreforma." In Juan de Herrera y su influencia. Actas del Simposio. Camargo, 14-17 julio 1992, dir. Miguel Ángel Aramburu-Zabala Higuera, coord. Javier Martínez Gómez, 197203. Santander: Fundación Obra Pía Juan de Herrera, Universidad de Cantabria.

Rodríguez y Gutiérrez de Ceballos, Alfonso. 2003. "Gótico versus Clásico: el principio de uniformidad de estilo en la construcción de la catedral nueva de Salamanca." In El comportamiento de las catedrales españolas. Del Barroco a los Historicismos, edited by Germán Ramallo Asensio, 15-22. Murcia: Universidad de Murcia, Consejería de Educación y Cultura, Fundación Cajamurcia.

Rosende Valdés, Andrés A. 2001. "La modificación de las tipologías tradicionales en el mundo moderno: la ampliación y reforma de las catedrales gallegas." In Las catedrales españolas en la Edad Moderna. Aproximación a un nuevo concepto del espacio sagrado, edited by Miguel Ángel Castillo Oreja, 51-84. Madrid: Fundación BBVA, A. Machado Libros.

Rúa Veloso, Olalla. 2005. Heráldica del Municipio de Mondoñedo. Lugo: Diputación Provincial de Lugo.

Saavedra Fernández, Pegerto. 1985. Economía, Política y Sociedad en Galicia: La provincia de Mondoñedo, 1480-1830. Madrid: Xunta de Galicia.

San Cristóbal Sebastián, Santos. 1989. La Catedral de Mondoñedo. Lugo: Diputación Provincial de Lugo.

San Cristóbal Sebastián, Antonio. 1998. "IV centenario de la ampliación de la catedral de Mondoñedo." Cuadernos del Museo Mindoniense 16: 47-67.

Sojo y Lomba, Fermín de. 1935. Los Maestros Canteros de Trasmiera. Madrid: Huelves y Compañía.

Vila Jato, María Dolores. 1998. "Los espacios construidos en tiempos de Felipe II." In El Reino de Galicia en la monarquía de Felipe II, 
coord. Antonio Eiras Roel, 499-521. Santiago de Compostela: Xunta de Galicia.

Vila Jato, María Dolores. 1999. "La actividad artística en la provincia de Mondoñedo durante el Renacimiento." Estudios Mindonienses 15: 459-468.

Villaamil y Castro, José. 1865. La Catedral de Mondoñedo. Su historia y descripción, sus pinturas murales, accesorios, moviliario, bronces y orfebrería, vestiduras y ropas sagradas. Madrid: M. Galiano.

Villaamil y Castro, José. 1889. "Los trascoros de las catedrales." Galicia Diplomática 4, no. 10 (Marzo 10): 75-76.
Yzquierdo Perrín, Ramón. 1985. “La arquitectura románica cisterciense." In Galicia Arte, edited by Francisco Rodríguez Iglesias, vol. 12, 20-67. A Coruña: Hércules.

Yzquierdo Perrín, Ramón. 2000. “Las Catedrales de la Diócesis de Mondoñedo en la Edad Media." In El legado cultural de la Iglesia Mindoniense. I Congreso do Patrimonio da Diócese de Mondoñedo. Ferrol, 16, 17, 18 de setembro, edited by Fátima Díaz Platas, Juan Manuel Monterroso Montero, Manuel José Recuero Astray, 103-163. A Coruña: Universidade da Coruña, Lugo: Diputación de Lugo. 
